\title{
El oficio de modelo para el dibujo del natural en la Real Academia de San Fernando entre 1752 y 1782
}

\section{The job of life-drawing modelling at the Royal Academy of San Fernando between 1752 and 1782}

\author{
Myriam Ferreira Fernández \\ Universidad Internacional de La Rioja (UNIR)
}

Fecha de recepción: 26 de abril de 2019

Fecha de aceptación: 27 de marzo de 2020

\author{
Anuario del Departamento de Historia y Teoría del Arte \\ vol. 32, 2020, pp. 73-95 \\ ISSN: 1130-5517, eISSN: 2530-3562 \\ https://doi.org/10.15366/anuario2020.32.004
}

\section{RESUMEN}

En este trabajo analizaremos el oficio de modelo en la Real Academia de Bellas Artes de San Fernando de Madrid desde su fundación en 1752 hasta 1782 basándonos en la documentación conservada sobre los modelos en el archivo de dicha Academia. Esta documentación permite reconstruir las características del oficio de modelo en la Academia: un oficio imprescindible para el dibujo del natural y el perfeccionamiento del dominio de la anatomía, pero poco valorado entre los profesores. Se comprueba cómo los modelos solían recibir un sueldo bajo, eran obligados a realizar labores domésticas, sufrían desprecios e insultos tanto dentro como fuera de la Academia y protagonizaban frecuentes faltas de disciplina. Además, se reconstruye el proceso de selección de los modelos, que permite apreciar cómo en los primeros años se preferían modelos jóvenes, altos y robustos, acordes al modelo clasicista propio de esa época, mientras que en el siglo XIX se preferirán modelos de diferentes edades y complexiones, mostrando una tendencia a un mayor realismo.

\section{PALABRAS CLAVE}

Real Academia de Bellas Artes de San Fernando. Neoclasicismo. Dibujo. Anatomía. Modelos.

\begin{abstract}
This article analyses the job of modelling at the Royal Academy of Fine Arts of San Fernando in Madrid, from its opening in 1752 to 1782 , through the documents about the models kept in the archive of the Academy. These documents allow us to reconstruct the features of the model profession at the Academy: essential for life drawing and mastering the representation of anatomy, but little valued among teachers. They show that models used to receive a low salary, were forced to carry out domestic chores, were despised and insulted both inside and outside the Academy and were often accused of lack of discipline. Besides, the process of selection of models shows that, in the early years of the Academy, young, tall and robust models were preferred, according to the classicist taste of the period, whilst models of different ages and complexions were preferred in the $19^{\text {th }}$ century, showing a tendency towards greater realism.
\end{abstract}

\section{KEY WORDS}

Royal Academy of Fine Arts of San Fernando. Neoclassicism. Drawing. Anatomy. Models. 
En el siglo XVIII, se consideraba que la culminación del proceso de aprendizaje de los artistas formados en las Academias era el dibujo del natural a través de modelos masculinos. En este trabajo, analizaremos el oficio de estos modelos en la Real Academia de Bellas Artes de San Fernando de Madrid, centrándonos especialmente en los primeros treinta años de esta institución, desde 1752 a 1782.

El estudio del natural en la Real Academia y el papel del dibujo del desnudo son temas que han sido tratados por diferentes autores, aportando datos interesantes sobre esta cuestión ${ }^{1}$. Sin embargo, al no tratarse de una parte esencial del proceso artístico, no se había realizado una investigación completa sobre el oficio de los modelos en el siglo XVIII, siendo el más completo hasta ahora el realizado por Esperanza Navarrete para el siglo XIX ${ }^{2}$. En este artículo queremos afrontar esa investigación, considerando que puede ofrecer aspectos de interés sobre la actividad y los objetivos de la Academia de San Fernando.

Para ello, hemos revisado la documentación existente sobre este tema en el archivo de la Real Academia de San Fernando, en especial el legajo que guarda la documentación específica sobre los modelos, así como otros dos legajos que recogen documentación sobre personal, en concreto sobre los porteros y sobre los subalternos fallecidos ${ }^{3}$. Para contar con más información, hemos procedido también a la lectura de las actas de las juntas de la Real Academia de San Fernando, tanto las ordinarias (incluidas las generales y las públicas) como las particulares ${ }^{4}$.

Hemos acotado como periodo de estudio desde 1752 hasta 1782, eligiendo los treinta primeros años de vida de la Academia, como periodo de consolidación y de definición de las funciones y de la actividad de los modelos. Sin embargo, en algunos casos, hemos incluidos datos que exceden este marco cronológico, pero guardan relación con las problemáticas planteadas en estos treinta primeros años.

Para facilitar el seguimiento de los personajes citados, hemos elaborado una tabla con los nombres de cada modelo y las fechas aproximadas en las que ejercieron como tales (fig. 1$)^{5}$.

\footnotetext{
1 Sobre este tema, ver Claude BÉDAT, La Real Academia de Bellas Artes de San Fernando (1744-1808), Madrid, Fundación Universitaria Española, 1989, pp. 135-137; Isabel AzCÁRATE et al., Historia y Alegoría: Los concursos de pintura de la Real Academia de Bellas Artes de San Fernando (1753-1808), Madrid, Real Academia de Bellas Artes de San Fernando, 1994, p. 13; Ascensión Ciruelos Gonzalo, "El dibujo en la Real Academia de San Fernando. Contribución al estudio de sus colecciones", Academia, 78 (1994), pp. 139-141; AA.VV., Los dibujos de la Academia, Madrid, Universidad Complutense, 1990; Elisa PovedAno, "Enseñanza de las Bellas Artes en España", en F. Castro Morales (coord.), Al-Andalus: una identidad compartida: arte, ideología y enseñanza en el protectorado español en Marruecos, Madrid, BOE, 1999, pp. 131-145; Tránsito DEL CERRO, "El desnudo en las Artes", A Parte Rei: Revista de Filosofia, 14 (2001), disponible en línea en http://serbal.pntic.mec.es/ cmunoz11/dessito.pdf [Consulta: 27 de marzo de 2020]; Ramón DíAz PADILLA, "El dibujo: base de la instrucción artística y lenguaje de expresión singular", en Patrimonio artístico de la Facultad de Bellas Artes: Inventario, Madrid, Consejo Social Universidad Complutense de Madrid, 2002, pp. 61-97; Almudena Negrete Plano, "Estudio y reflejo de la Antigüedad en el arte a través de los vaciados de yeso", en C. Sánchez Fernández (coord.), Dioses, héroes y atletas: la imagen del cuerpo en la Grecia antigua, Madrid, Comunidad de Madrid, Museo Arqueológico Regional, 2015, pp. 251-264; Milagros AlgabA y María NaGore, Arte y carne. La anatomía a la luz de la Ilustración, Madrid, Universidad Complutense de Madrid, 2016; Ramón DíAz PADILLA, El dibujo del natural, Madrid, Akal, 2007; Juan Antonio SÁNCHEZ LóPEZ, "Del ideal atlético al ideal heroico. Algunas controversias [pre y post] barrocas", en C. González Román (ed.), A través de la mirada, Madrid, Abada, 2014, pp. 81-126; Carlos REYERO Hermosilla, "De la forma ideal al cuerpo sexuado: El modelo del natural en la Academia”, en C. Sánchez Fernández (coord.), Dioses, héroes y atletas: la imagen del cuerpo en la Grecia antigua, Madrid, Comunidad de Madrid, Museo Arqueológico Regional, 2015, pp. 265-276.

2 Esperanza Navarrete Martínez, La Academia de Bellas Artes de San Fernando y la pintura en la primera mitad del siglo XIX, Madrid, Fundación Universitaria Española, 1999, pp. 145-147.

3 "Secretario general. Personal. Modelos", Archivo de la Real Academia de Bellas Artes de San Fernando (ARABASF), leg. 1-46-4 (1748-1856); "Secretario general. Personal. Porteros, conserjes y mozos", ARABASF, leg. 1-45-4 (1745-1845); "Secretario general. Personal. Viudas de empleados", ARABASF, leg. 1-46-5 (1772-1841).

4 “Actas. Sesiones ordinarias", ARABASF, leg. 3-81 (1752-1757), leg. 3-82 (1757-1769), leg. 3-84 (1776-1785); “Actas. Sesiones particulares”, ARABASF, leg. 3-121 (1757-1769), leg. 3-122 (1770-1775), leg., 3-123 (1776-1785), leg. 3-124 (1786-1794).

5 Ver el recuento de los modelos hecho por el conserje Juan Moreno en 1782: “Actas. Sesiones particulares”, ARABASF, leg. 3-123 (1776-1785), 6 de octubre de 1782, fol. 236r.
} 


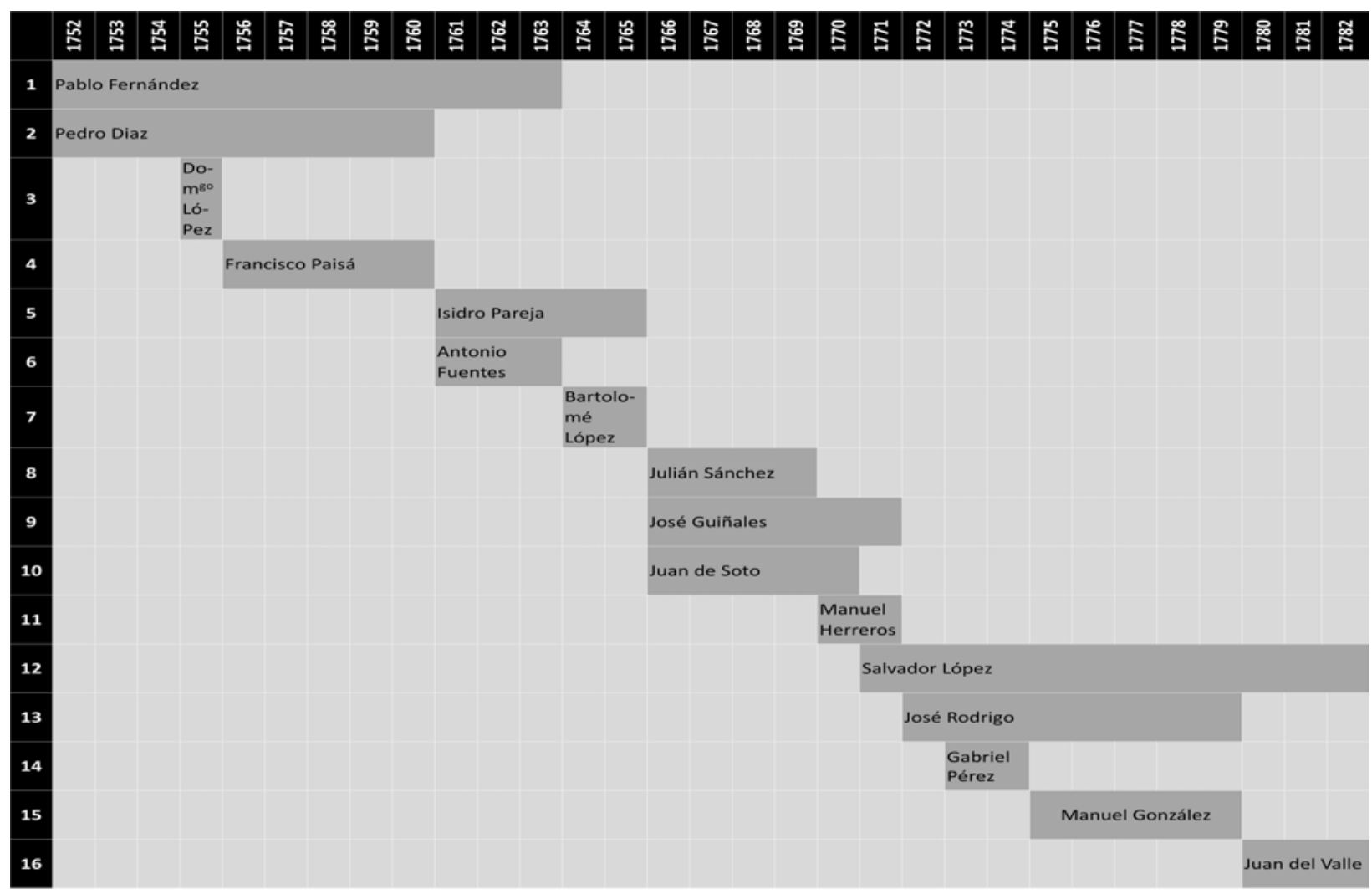

Fig. 1. Modelos de la Real Academia de San Fernando (1752-1782), elaboración propia.

\section{EI dibujo del natural en la Real Academia de Bellas Artes de San Fernando}

La creación en 1752 de la Real Academia de Bellas Artes de San Fernando supuso la introducción en España de un modelo bastante novedoso respecto al panorama artístico de la época. En este país, el dibujo del desnudo imitando modelos de la Antigüedad no se había difundido excesivamente durante el siglo XVIII: el realismo característico de la escuela española hacía que Pacheco, por ejemplo, considerara que la cima de un artista era pintar un bodegón o un retrato ${ }^{6}$, mientras que los desnudos eran despreciados por bastantes de los artistas (como Palomino o el propio Pacheco) y castigados por algunas autoridades eclesiásticas ${ }^{7}$. Sin embargo, la Real Academia se había desarrollado a partir del taller del escultor Gian Domenico Olivieri, cuyo origen italiano hacía que tuviera un gran interés en promover el dibujo del natural, muy habitual en su país desde el siglo XVI. En efecto, el dibujo del cuerpo humano se había convertido en una de las bases de las Academias fundadas en Italia a partir del siglo XVI, como la Accademia di San Luca de Roma, la primera en reglamentar este tipo de enseñanzas ${ }^{8}$ o la Accademia del Nudo, creada ya en el siglo XVIII por orden papal ${ }^{9}$. De hecho, según Elisa Povedano, "el objetivo principal de las [academias] italianas en el siglo XVI era la reunión de sus miembros para «dibujar del desnudo»"10. Este tipo

\footnotetext{
6 Alejandro Torres Fiori, "Francisco Pacheco. La Academia de Sevilla, la tratadística y su relación con Diego Velázquez", Tesis doctoral, Palma, Universitat de les Illes Balears, 2018, pp. 23-24.

7 Carlos García PeÑa, “La Venus italiana de Velázquez”, Cuadernos de filología italiana, 10 (2003), p. 86.

8 Díaz Padilla, 2002, pp. 63-64.

9 Carlo Pietrangeli, "L’Accademia del Nudo in Campidoglio", Strenna dei romanisti, 20 (1959), pp. 123-128.

10 Povedano, 1999, p. 132; Díaz Padilla, 2007, p. 16.
} 
de aprendizaje se extenderá por el resto de academias europeas, como la Académie Royale de Francia, fundada en $1648^{11}$, o la Royal Academy de Inglaterra, creada en $1768^{12}$.

Por ello, ya en 1744, la Junta Preparatoria asumió esta enseñanza, generalizando la existencia en la Academia de clases de dibujo del natural, con modelo desnudo ${ }^{13}$. La importancia dada a esta disciplina hará que la propia Academia de San Fernando diga, en la entrega de premios de 1793, que los modelos son "como unos libros clásicos en el estudio del diseño"14.

\section{La función de los modelos}

El dibujo del natural se consideraba, como hemos dicho, la culminación del aprendizaje académico, por lo que estaba reservado para los estudiantes más avanzados, que llevaban ya años de formación en la

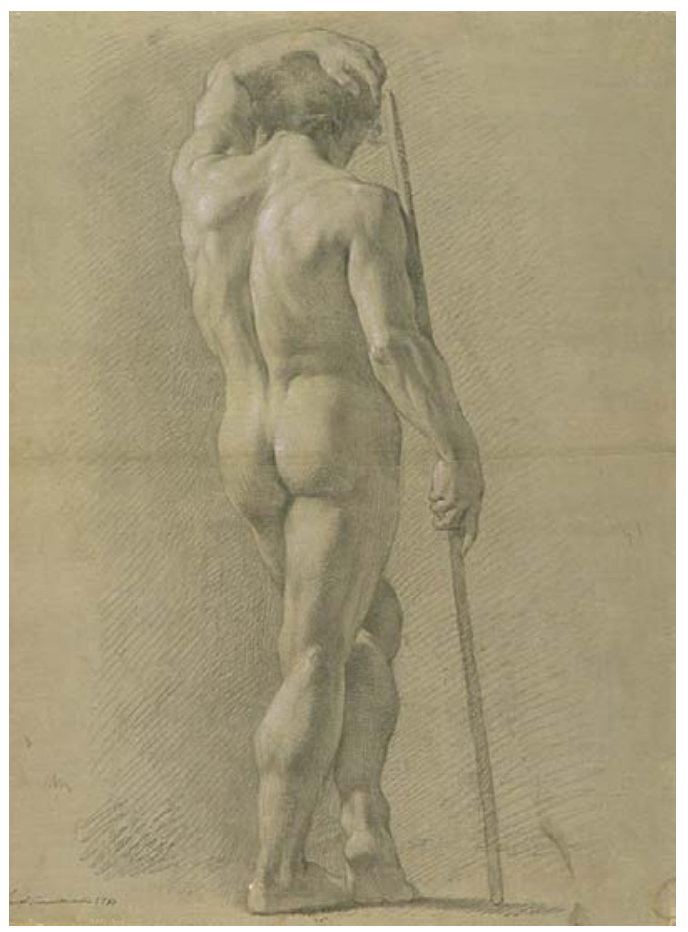

Fig. 2. José Camarón, Desnudo masculino de espaldas y en pie sujetando una pértiga, 1780, carbón y toques de clarión, 550x384 mm. Madrid, Colección de Dibujos Antiguos de la Biblioteca de la Facultad de Bellas Artes de la Universidad Complutense de Madrid [I.P.A.F.B.A. No $\left.{ }^{\circ} 1933\right]$.

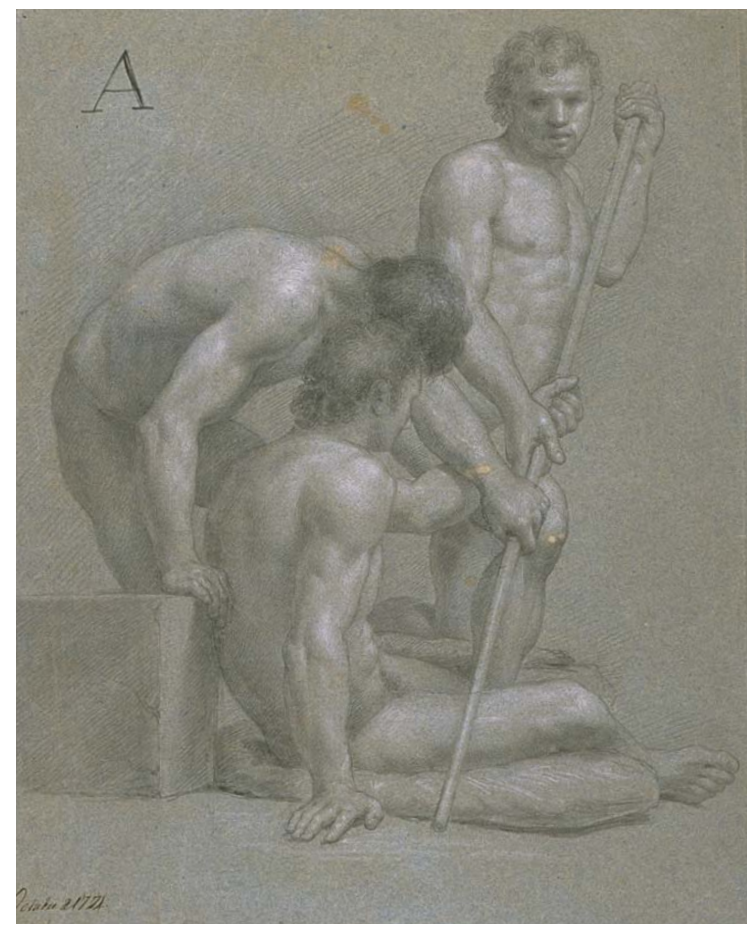

Fig. 3. Agustín Esteve, Tres desnudos masculinos (uno yacente y los otros tratando de ayudarle), 10/1771, lápiz y toques de clarión, $535 \times 410 \mathrm{~mm}$. Madrid, Colección de Dibujos Antiguos de la Biblioteca de la Facultad de Bellas Artes de la Universidad Complutense de Madrid [I.P.A.F.B.A. $\left.\mathrm{N}^{\circ} 1978\right]$.

11 La Académie royale fue abolida en 1793, siendo sustituida en 1795 por la École des Beaux Arts.

12 Susan Waller, "Professional Poseurs: The Male Model in the Ecole des Beaux-Arts and the Popular Imagination", Oxford Art Journal, 25, 2 (2002), pp. 41-64; Anne Carol DARLington, "The Royal Academy of Arts and its anatomical teachings", Tesis doctoral, Londres, University of London, 1990.

13 “Secretario general. Personal. Modelos", ARABASF, leg. 1-46-4 (1748-1856), 20 de mayo de 1744, s/f.

14 José CAVedA, Memorias para la historia de la Real Academia de San Fernando y de las Bellas Artes en España, Madrid, Imprenta de Manuel Tello, 1867, vol. I, p. 293. 
Academia copiando dibujos y esculturas de la Antigüedad. Estas salas eran dirigidas por un Teniente de la Academia, mientras que la enseñanza del natural era responsabilidad de los Directores ${ }^{15}$.

El Director tenía la obligación de ocuparse de la colocación de los modelos delante de los estudiantes que, situados en semicírculo delante de ellos, trataban de representar fielmente la anatomía humana en distintas posturas y posiciones. Por lo general, se buscaban posturas tensas que mostraran mejor la plasticidad del cuerpo humano, aunque eso exigiera un gran esfuerzo a los modelos (fig. 2). La última semana de cada mes se contaba con la presencia de todos los modelos, con los que se disponía un grupo de figuras, una composición aún más complicada de dibujar que una figura aislada (fig. 3) ${ }^{16}$.

Las poses escogidas podían representar actividades deportivas al modo de la Grecia Antigua, representaciones alegóricas (fig. 4), figuras religiosas (fig. 5) o acciones militares y heroicas (figs. 6 y 7).

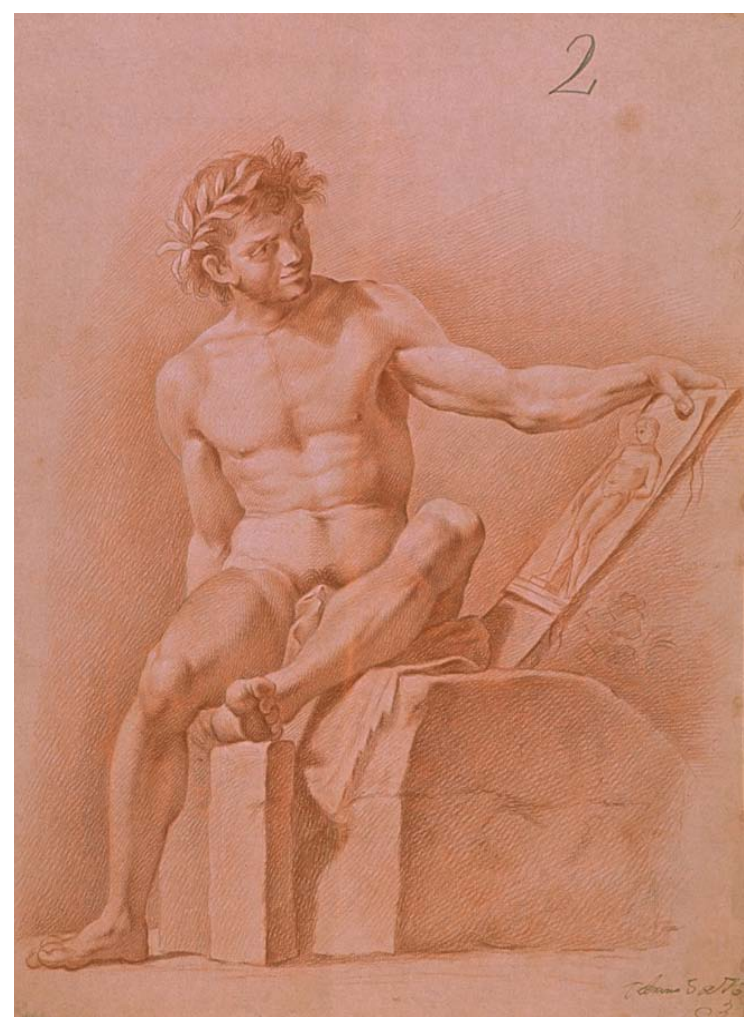

Fig. 4. José Mayne, Desnudo masculino sentado sobre bloques cúbicos y visto de frente, 05/02/1776, sanguina y toques de clarión, 520x396 mm. Madrid, Colección de Dibujos Antiguos de la Biblioteca de la Facultad de Bellas Artes de la Universidad Complutense de Madrid [I.P.A.F.B.A. No 2050].

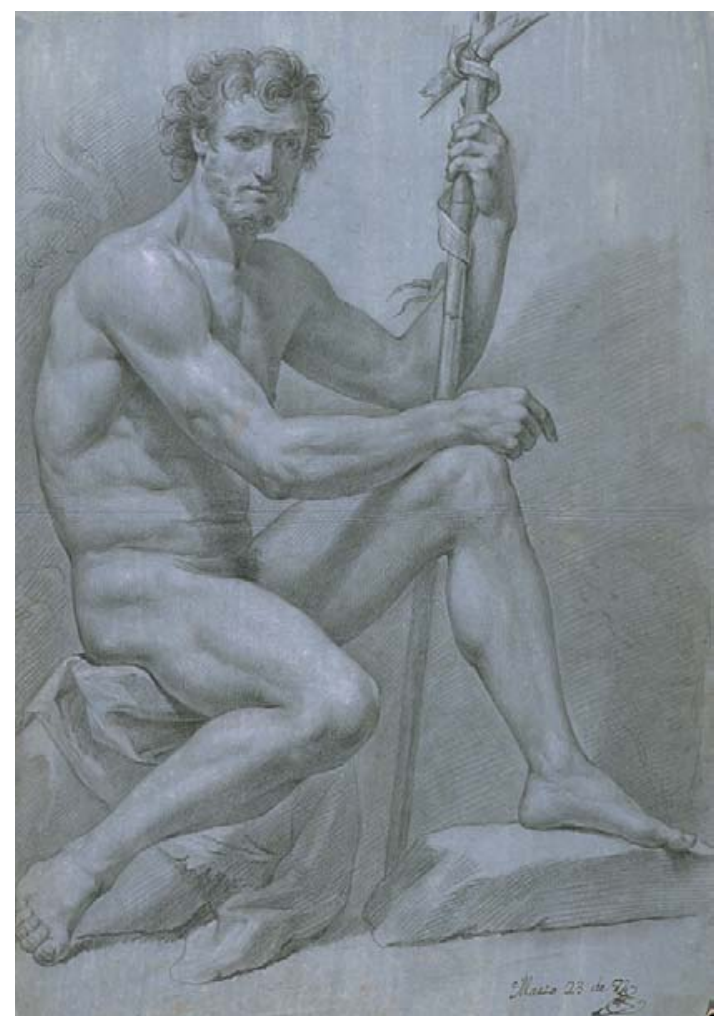

Fig. 5. José Maea, ¿San Juan Bautista?, 23/03/1782, lápiz y toques de clarión, 550x405 mm. Madrid, Colección de Dibujos Antiguos de la Biblioteca de la Facultad de Bellas Artes de la Universidad Complutense de Madrid [I.P.A.F.B.A. $\left.\mathrm{N}^{\circ} 2019\right]$.

\footnotetext{
15 Estatutos de la Real Academia de S. Fernando, Madrid, Gabriel Ramírez, 1757, pp. 50 y 51.

16 Ibidem.
} 


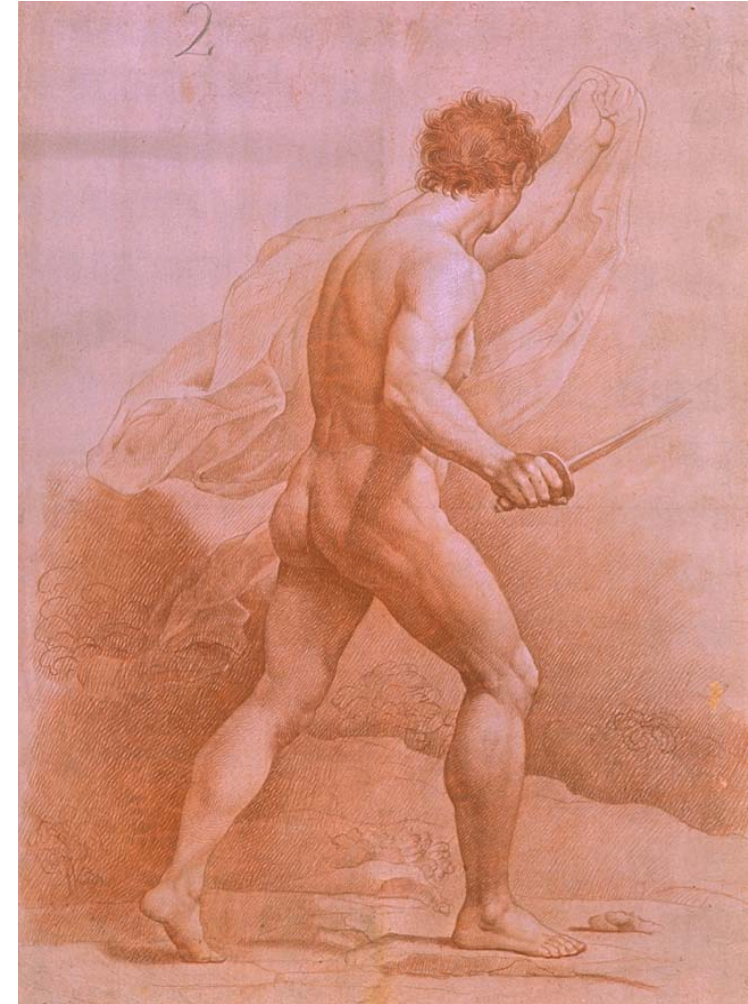

Fig. 6. Juan Navarro, Desnudo masculino caminando con una daga y una tela en fondo de paisaje, 05/03/1776, sanguina y toques de clarión, 562×398 mm. Madrid, Colección de Dibujos Antiguos de la Biblioteca de la Facultad de Bellas Artes de la Universidad Complutense de Madrid [I.P.A.F.B.A. No 2064].

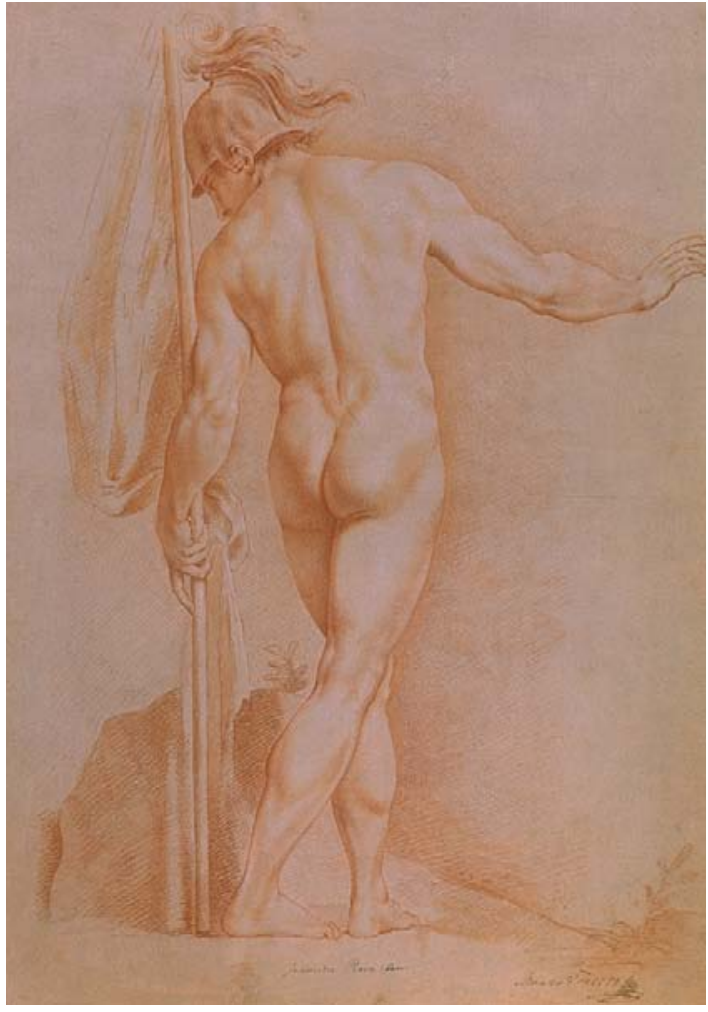

Fig. 7. Francisco Pérez, Desnudo masculino caminando de espaldas con casco y bandera, 08/03/1779, sanguina y toques de clarión, 550x400 mm. Madrid, Colección de Dibujos Antiguos de la Biblioteca de la Facultad de Bellas Artes de la Universidad Complutense de Madrid [I.P.A.F.B.A. No 2071].

\section{Características de los modelos}

Acorde sobre todo a esta caracterización deportiva y heroica, se solía esperar de los modelos que fueran jóvenes, altos, robustos, bien proporcionados y sin defectos físicos visibles. Así, por ejemplo, ya en 1755, al buscar un nuevo modelo que trabajara en la Academia, se determinó que el seleccionado debía ser “de estatura más robusta y más joben que los dos antiguos"17. En 1770, al examinar a un posible modelo llamado Santiago Martínez, se alabó que medía "de altura dos baras y cinco dedos"18 y de otro candidato llamado Gabriel Pérez, se indicó que era "sujeto de nueve quarttos y una pulgada de estatura y bien formado y de la corresp[ondient]e robuztes [sic] para modelo" "19. De Manuel González se especificó que era "un hombre bien formado" 20 y de Manuel Herreros que estaba "ad/mirablemente formado"21. Esta "buena formación" se desglosaba en ocasiones en otros valores: de Santiago Martínez también se indicaba que "además de la proporción elegante del todo, es limpio y de buen color"22 y de Salvador López se alababa

\footnotetext{
17 “Actas. Sesiones ordinarias”, ARABASF, leg. 3-81 (1752-1757), 22 de octubre de 1755, fol. 40r.

18 "Secretario general. Personal. Modelos", ARABASF, leg. 1-46-4 (1748-1856), 10 de junio de 1770, s/f.

19 “Actas. Sesiones ordinarias", ARABASF, leg. 3-83 (1770-1775), 5 de diciembre de 1773, fol. 231v.

20 “Actas. Sesiones ordinarias", ARABASF, leg. 3-83 (1770-1775), 9 de octubre de 1774, fol. 301r y v.

21 "Actas. Sesiones ordinarias", ARABASF, leg. 3-82 (1757-1769), 29 de octubre de 1769, fol. 568v-569r.

22 "Secretario general. Personal. Modelos", ARABASF, leg. 1-46-4 (1748-1856), 23 de mayo de 1770, s/f.
} 
su "buena simetría y proporción"23. Todavía en 1792 al buscar un nuevo modelo se puso como requisito que fuera "hombre de buena estatura y bien proporcionado"24.

El modelo que se buscaba, por lo tanto, era más el del Doríforo que el de una figura praxiteliana. No se valoraba positivamente que un modelo fuera esbelto y, en el caso de Salvador López, se dudó mucho en contratarlo porque se pensaba que era demasiado delgado ${ }^{25}$.

Además, los defectos físicos se consideraban incompatibles con la labor de modelo. En el caso del ya citado Santiago Martínez, Antonio González criticó "los / dedos de los pies que los tiene engarabitados aunque no de mala forma" 26 . Felipe de Castro coincidió con esa apreciación: "le halló un buen modelo excepto en los pies como vm dice", pero aun así decidió proponer su contratación ${ }^{27}$. En cambio, el Viceprotector, al enterarse de que "Santiago Martínez tiene defectuosos los pies, aunque en todo lo demás es muy bueno", propuso no llevar a cabo su contratación y esperar unos meses para encontrar otro modelo ${ }^{28}$.

\section{El número de los modelos}

Cuando se creó la Real Academia en 1752, los modelos del natural eran dos, los mismos que ya existían desde los tiempos de la Junta Preparatoria ${ }^{29}$. En 1755, con el crecimiento de los estudios se decidió contratar a un tercer modelo ${ }^{30}$, pasando a ser desde ese momento tres los modelos previstos en la Academia. Aun así, los estatutos de 1757 mostraban cierta flexibilidad, indicando que en la Academia habría "dos o tres hombres bien formados para Modelos"31.

Sin embargo, no siempre se contó con tres modelos trabajando en la Academia, ya que las dificultades para encontrar modelos bien formados o los despidos imprevistos por faltas graves de comportamiento hicieron que en ocasiones hubiera solo dos modelos contratados. Así en 1781, la Academia se quejaba de "la dificultad de encontrar sujetos de buenas proporciones que quieran sujetarse a este exercicio como lo acredita no tener la / Academia actualmente más que dos modelos debiendo tener tres" ${ }^{32}$. E incluso un modelo, José Guiñales, se quejaba tiempo después de que el trabajo le había "cogido varias veces solo" 33 , lo que indica la poca estabilidad de los modelos en esos momentos.

\section{La selección de modelos}

La búsqueda de aspirantes al puesto de modelo solía ser responsabilidad del conserje. Este debía anunciar la vacante existente, habitualmente poniendo carteles en los alrededores de la Academia que invitaban a los aspirantes a solicitar información al conserje. En 1779, por ejemplo, se indicaba que se había convo-

\footnotetext{
23 "Secretario general. Personal. Modelos", ARABASF, leg. 1-46-4 (1748-1856), 1786, s/f.

${ }^{24}$ Diario de Madrid, 21 de diciembre de 1792, p. 1483.

25 "Secretario general. Personal. Modelos", ARABASF, leg. 1-46-4 (1748-1856), 9 de mayo de 1770, s/f.

26 “Secretario general. Personal. Modelos", ARABASF, leg. 1-46-4 (1748-1856), 20 de mayo de 1770, s/f.

27 “Secretario general. Personal. Modelos", ARABASF, leg. 1-46-4 (1748-1856), 23 de mayo de 1770, s/f.

28 “Actas. Sesiones ordinarias", ARABASF, leg. 3-83 (1770-1775), 10 de junio de 1770, fol. 24v.

29 "Actas. Sesiones ordinarias", ARABASF, leg. 3-81 (1752-1757), 11 de julio de 1755, fol. 39v.

30 “Actas. Sesiones ordinarias", ARABASF, leg. 3-81 (1752-1757), 22 de octubre de 1755, fol. 40r.

31 Estatutos de la Real Academia de S. Fernando, Madrid, Gabriel Ramírez, 1757, p. 10. Cfr. BÉDAT, 1989, p. 129.

32 "Secretario general. Personal. Modelos", ARABASF, leg. 1-46-4 (1748-1856), 25 de enero de 1781, s/f. Ver otro caso en “Actas. Sesiones ordinarias”, ARABASF, leg. 3-82 (1757-1769), 11 de febrero de 1763, fol. 164v.

33 "Secretario general. Personal. Modelos", ARABASF, leg. 1-46-4 (1748-1856), 1 de junio de 1803, s/f.
} 
cado a los candidatos "en virtud de los carteles que se pusieron en las esquinas" 34 . En ocasiones, aunque raramente, también se anunciaba la vacante en los periódicos. En octubre de 1760 se decidió buscar un nuevo modelo "publicando para ello la vacante con todas sus circunstancias por medio del Diario, y por todos los demás que sean oportunos, para que llegue a noticias de todos y haya más en que escojer" 35 , como se hizo el 31 de octubre de 1760 en el Diario noticioso universal ${ }^{36}$. Sin embargo, no parece que los anuncios de prensa volvieran a utilizarse hasta $1792^{37}$.

Según los estatutos de 1757, la elección de los modelos dependía del Director General, que debía proponer a la Junta Ordinaria los que le parecieran más a propósito, aunque los profesores debían realizar una votación para elegir o no a cada candidato ${ }^{38}$. En ocasiones, sin embargo, el Director General delegaba o se apoyaba en otros profesores para esta labor. En 1763, por ejemplo, siendo Director General Felipe de Castro, fueron Antonio González, Andrés Calleja y Juan Pascual de Mena los encargados de seleccionar a un nuevo modelo ${ }^{39}$. Y en 1770, siendo Director General Antonio González, solicitó la colaboración de Felipe de Castro, quien examinaba a los candidatos después de González y le enviaba a este sus impresiones por escrito ${ }^{40}$.

\section{La dedicación de los modelos}

La docencia en las salas de la Academia se iniciaba al atardecer, por lo que los modelos trabajaban únicamente en horario de noche. Inicialmente solo acudía aquel que tenía turno, pero en 1763 se estableció que acudieran los tres todos los días, para que el profesor encargado de la sala eligiera al que considerara más conveniente para la figura que se quería componer, o decidiera si había que continuar con una figura comenzada aunque hubiera terminado el turno de ese modelo, compensando después la asistencia del resto ${ }^{41}$.

Esta dedicación permitía que los modelos desempeñaran otras labores durante el día, lo cual hacía que el oficio de modelo fuera solamente un complemento de su trabajo habitual. En varios casos, sabemos cuál era ese trabajo habitual al que se dedicaban. Los dos primeros modelos de la Academia, Pedro Díaz y Pablo Fernández, eran peones en las obras de la Real Fábrica, aunque su oficio de modelo solía permitir que se les asignaran trabajos poco duros que no les afectaran físicamente ${ }^{42}$. José Guiñales, Manuel Herrera y Santiago Martínez eran soldados: el primero "estaba sirviendo de soldado en el Regimiento Inmemorial del Rey", en concreto en el Regimiento de Castilla; el segundo servía en el "Regimiento de guardias españolas" y el tercero había servido, durante once años, también en el cuerpo de Guardias Españoles ${ }^{43}$.

Por último, también había modelos que no tenían ninguna ocupación cuando fueron contratados por la Academia: así, en 1781 el modelo Juan del Valle fue hecho "preso por vago" 44 y, aunque se interce-

\footnotetext{
34 "Secretario general. Personal. Modelos", ARABASF, leg. 1-46-4 (1748-1856), 18 de noviembre de 1779, s/f; "Actas. Sesiones ordinarias", ARABASF, leg. 3-82 (1757-1769), 2 de octubre de 1763, fol. 210r.; "Actas. Sesiones ordinarias", ARABASF, leg. 3-84 (1776-1785), 5 de diciembre de 1779, fol. 138v.-139r.

35 "Actas. Sesiones ordinarias", ARABASF, leg. 3-82 (1757-1769), 28 de octubre de 1760, fol. 100v.

36 Diario noticioso, curioso, erudito y comercial público y económico, 31 de octubre de 1760, fol. 126.

37 Diario de Madrid, 21 de diciembre de 1792, p. 1483.

38 Estatutos de la Real Academia de S. Fernando, Madrid, Gabriel Ramírez, 1757, p. 82; NAVArRete MARTíneZ, 1999 , p. 113.

39 “Actas. Sesiones ordinarias", ARABASF, leg. 3-82 (1757-1769), 2 de octubre de 1763, fol. 210r.

40 "Secretario general. Personal. Modelos", ARABASF, leg. 1-46-4 (1748-1856), 9 de mayo de 1770, s/f y 20 de mayo de $1770, \mathrm{~s} / \mathrm{f}$

41 “Actas. Sesiones ordinarias", ARABASF, leg. 3-82 (1757-1769), 1 de mayo de 1763, fol. 169v.-170r. Cfr. Estatutos de la Real Academia de S. Fernando, Madrid, Gabriel Ramírez, 1757, pp. 50 y 51.

42 “Actas. Sesiones ordinarias", ARABASF, leg. 3-81 (1752-1757), 11 de julio de 1755, fol. 39v.

43 "Secretario general. Personal. Modelos", ARABASF, leg. 1-46-4 (1748-1856), 1770, s/f.

44 "Secretario general. Personal. Modelos", ARABASF, leg. 1-46-4 (1748-1856), 25 de enero de 1781, s/f.
} 
dió por su liberación, la Academia tuvo que reconocer que Valle se caracterizaba por "su natural amigo de diversiones" 45 .

\section{Un caso especial: Salvador López, relojero}

Un caso especial en la actividad profesional de los modelos es el de Salvador López. Fue contratado como modelo en 1770, probablemente siendo bastante joven, ya que sirvió como modelo casi dieciocho años ${ }^{46}$. Además, frente a los problemas de indisciplina que, como veremos, ocasionaron otros modelos, López parece haber tenido un carácter más apacible: eran raras sus ausencias ${ }^{47}$, se ofrecía a trabajar durante el verano ${ }^{48}$ y acudía a los talleres de los profesores cuando estos necesitaban un modelo del natural ${ }^{49}$.

Por las fechas en las que trabajó y la coincidencia de rasgos faciales, podríamos incluso plantear la hipótesis de cuál de los modelos dibujados por los discípulos de la Academia podría ser Salvador López (figs. 8 y 9).

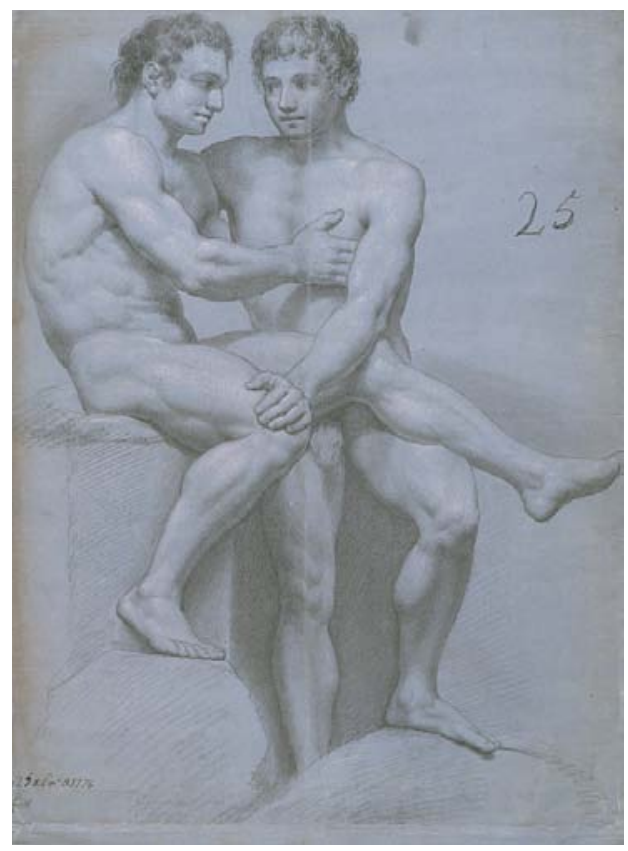

Fig. 8. Agustín Esteve Marqués, Dos desnudos masculinos sentados y entrelazados, 25/01/1776, lápiz y toques de clarión, 570x430 mm. Madrid, Colección de Dibujos Antiguos de la Biblioteca de la Facultad de Bellas Artes de la Universidad Complutense de Madrid [I.P.A.F.B.A. No 1979].

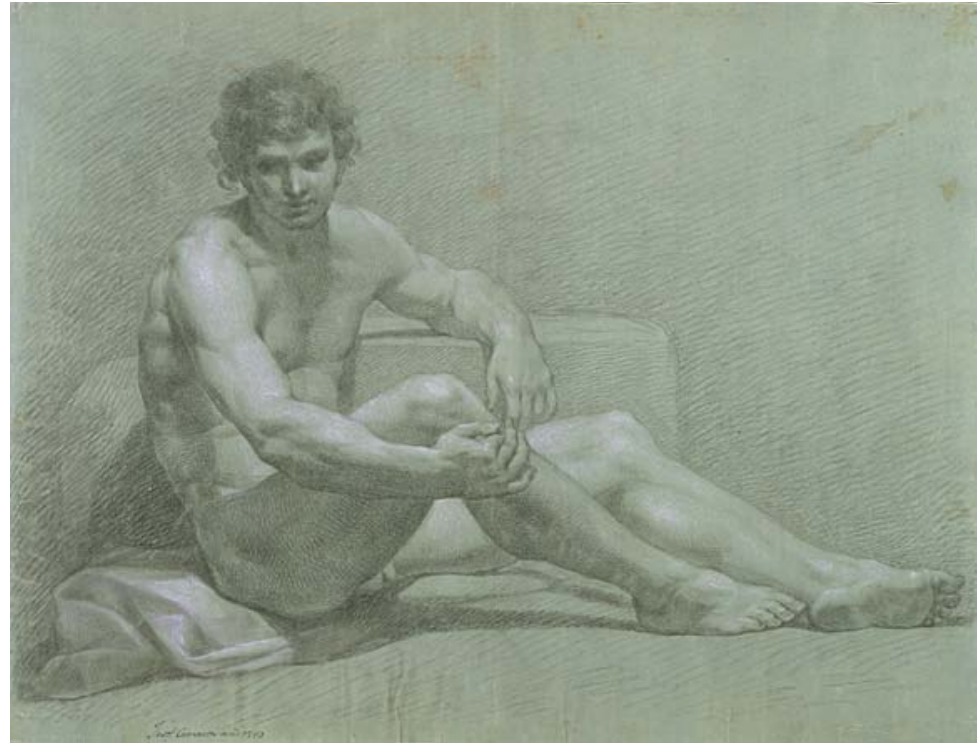

Fig. 9. José Camarón, Desnudo masculino sentado en el suelo agarrándose la rodilla derecha, 1780, carbón y toques de clarión, 390x523 mm. Madrid, Colección de Dibujos Antiguos de la Biblioteca de la Facultad de Bellas Artes de la Universidad Complutense de Madrid [I.P.A.F.B.A. $\mathrm{N}^{\circ}$ 1934].

\footnotetext{
45 “Actas. Sesiones particulares”, ARABASF, leg., 3-123 (1776-1785), 6 de octubre de 1782, s/f.

46 "Secretario general. Personal. Modelos", ARABASF, leg. 1-46-4 (1748-1856), 1786, s/f.

47 "Secretario general. Personal. Modelos", ARABASF, leg. 1-46-4 (1748-1856), 5 de septiembre de 1779, s/f.

48 “Actas. Sesiones ordinarias”, ARABASF, leg. 3-83 (1770-1775), 3 de julio de 1774, fol. 283r. y v.

49 "Secretario general. Personal. Modelos", ARABASF, leg. 1-46-4 (1748-1856), 5 de noviembre de 1780, s/f.
} 
En algún momento que desconocemos, López empezó a interesarse por la relojería. No había tenido formación como aprendiz de ningún relojero, pero incluso de forma autodidacta logró adquirir una gran habilidad:

él mismo refunde y trabaja todas las piezas, las afina y hace q[uant]to hai que hacer, todo por pura inclin[aci]on y asiduo exercicio, reducido a trabajar en el hueco de una vent[an]a inter[i]or de la Acad[emi]a donde tien[e] form[a]do su taller ${ }^{50}[\ldots]$, admirándose los que ven esta y otras obras que ha con registros de repetic[i]on y música, lo que ha podido en él la const[anci]a y medit[aci]ón ${ }^{51}$.

Viendo esa habilidad, hacia 1778 el duque de Abrantes le encargó que realizara un reloj para la Sala de Principios de la Academia ${ }^{52}$. López requirió un año de trabajo, pero logró terminarlo a satisfacción del cliente. Entusiasmado con el resultado, en 1779 escribió un memorial al Viceprotector "en que pedía se dignase esta concederle el título de su relojero para lograr de este modo parroquianos, y mantener sus obligaciones" 53 . La Junta, sin embargo, "consideró extravagancia que este Cuerpo haya de dar títulos de Relojeros, pareció mejor a los Sres. que al cabo del año se le conceda alguna remuneración a dicho Salvador López, quien deberá mantener siempre el reloj en buen estado"54.

López continuó trabajando en la Academia pero, al parecer, deseando que surgiera la ocasión de volcarse en la relojería o en alguna otra actividad. En 1780 solicitó su jubilación como modelo y pasar a trabajar como barrendero. Sin embargo, no se le concedió porque se consideró que podía seguir sirviendo ${ }^{55}$. En 1782, tras el despido de los otros dos modelos de la Academia, se planteó la posibilidad de jubilar también a Salvador, ya que era quien más tiempo llevaba sirviendo, pero se desechó esta idea por considerar que, a pesar del tiempo transcurrido, su cuerpo no había sufrido apenas cambios ${ }^{56}$.

Finalmente, en 1786, Salvador López consiguió un puesto de trabajo gracias a su labor como relojero. En 30 de septiembre de 1786, expuso que "S.M. (que Dios gu[ard]e) se ha dignado nombrarle Reloxero de su R[ea]l Gabinete de Historia Natural con señalamiento de tres mil reales anuales que devera percibir de la R[en]ta de Gaceta con la indispensable obligación de instruir a la Juventud en la perfección de este arte" 57 . La Academia asumió la partida de López y acordó darle 400 reales "en atención a sus servicios" 58.

La labor de López como relojero del Real Gabinete ha sido analizada en otras publicaciones ${ }^{59}$, aunque en su mayoría sin hacer referencia a su labor previa como modelo de la Academia. Por lo que toca a esta institución, podemos indicar que López aún aspiraba a trabajar en ella como relojero, por lo que en 1791, "se leyó un memorial de Salvador López, modelo antiguo de la Academia en que recordando sus servicios decía se le diese algún cargo y asignación en ella, como de su Relojero. No habiendo lugar tal solicitud, fue desechada" 60 .

50 Sobre la concesión de este cuarto, “Actas. Sesiones particulares”, ARABASF, leg. 3-123 (1776-1785), 4 de febrero de 1781, fol. $203 \mathrm{v}$.

51 "Secretario general. Personal. Modelos", ARABASF, leg. 1-46-4 (1748-1856), 1786, s/f.

52 "Actas. Sesiones particulares", ARABASF, leg. 3-123 (1776-1785), 7 de marzo de 1779, fol. 131v.-132r.

53 “Actas. Sesiones particulares", ARABASF, leg. 3-123 (1776-1785), 7 de marzo de 1779, fol. 132r.; "Secretario general. Personal. Modelos", leg. 1-46-4 (1748-1856), 7 de marzo de 1779, s/f.

54 “Actas. Sesiones particulares", ARABASF, leg. 3-123 (1776-1785), 7 de marzo de 1779, fol. 132r.

55 "Secretario general. Personal. Modelos", ARABASF, leg. 1-46-4 (1748-1856), 5 de noviembre de 1780, s/f.

56 "Secretario general. Personal. Modelos", ARABASF, leg. 1-46-4 (1748-1856), 5 de mayo de 1782, s/f.

57 “Actas. Sesiones particulares", ARABASF, leg. 3-124 (1786-1794), 1 de octubre de 1786, fol. 47r y v.

58 “Secretario general. Personal. Modelos", ARABASF, leg. 1-46-4 (1748-1856), 3 de octubre de 1786, s/f.

59 Ver, por ejemplo, M. Carmen Velasco PéREz, "Salvador López, relojero del real gabinete de historia natural", Madrid histórico, 6 (2006), pp. 38-43; José Luis BASANTA CAMPos, "López, Salvador”, en G. Anes (dir.), Diccionario Biográfico Español, Madrid, Real Academia de la Historia, 2011, t. 30, p. 272. Cfr. Paulina JunQuERA, Relojería palatina. Antología de la Colección Real Española, Madrid, Roberto Carbonell, 1956.

60 “Actas. Sesiones particulares", ARABASF, leg. 3-124 (1786-1794), 13 de marzo de 1791, fol. 160v; "Secretario general. Personal. Modelo", ARABASF, leg. 1-46-4 (1748-1856), 24 de febrero de 1791, s/f. 


\section{Las tareas domésticas}

Además de posar para los dibujos de los estudiantes, la Academia preveía que los modelos ayudaran también en el mantenimiento y limpieza de la sede, como los demás subalternos o criados de la misma. Así, bajo las órdenes de los conserjes y en colaboración con los porteros y barrenderos de la Academia, tenían obligaciones como barrer el suelo o mantener encendidos los braseros que calentaban la sala. Los estatutos de 1757 recogían estas obligaciones, estipulando que los modelos ayudarían al conserje en "el aseo y cuidado de los muebles, alajas y salas de la Academia" 61 y también colaborarían con los porteros en tareas como "el aseo y limpieza de las salas, de tenerlas abiertas en los días y horas de estudio, y de prevenir las luces y braseros" $"$. Sin embargo, este requisito de realizar tareas domésticas fue la principal fuente de fricciones entre la Academia y los modelos.

En 1759 los porteros se quejaron de que los tres modelos no ayudaban nunca en lo que se les mandaba, así que la Junta ordenó "que desde el presente día los modelos turnen en barrer toda la Casa de la Panadería quando lo necesite a disposición del Conserje. Que sea de su cargo encender los braseros sin escusa ni réplica alguna y con la prevención de que al que no obedeciese por el mismo hecho y sin esperar a más se le despedirá" ${ }^{63}$.

Sin embargo, en 1763 el Secretario de la Academia volvió a quejarse de los modelos, "no sirviendo estos como están obligados para limpiar y asear la casa y salas por más amonestaciones y prevenciones que se les han hecho". En este caso, la Academia decidió despedir a los tres modelos y reducir el sueldo de los nuevos que se contrataran. Sin embargo, en cuanto a las tareas domésticas, se renunciaba a pedírselas a los modelos y se proponía la contratación de un nuevo barrendero que las asumiera ${ }^{64}$.

A favor de descargar a los modelos de estas obligaciones domésticas se pronunció también Anton Rafael Mengs en su célebre propuesta de reforma de la Real Academia, realizada en $1766^{65}$. Mengs realizó esta propuesta a la Junta Particular de la Academia para que los estudiantes pudieran "hacer con más fruto que asta aora los estudios" de Pintura y Escultura. Y su primera providencia "indispensable" hacía referencia precisamente a los modelos:

Primera, que se busque un hombre lo más perfectamente formado $\mathrm{q}[\mathrm{u}] \mathrm{e}$ sea posible para modelo: el cual no tenga otro destino ni ocupación $\mathrm{q}[\mathrm{u}] \mathrm{e}$ esté pronto a servir de día y de noche siempre que se le mande, aunq[u]e para ello sea necesario darle más salario que a los actuales, que son mal formados y de consiguiente inútiles; y q[u]e para atraer a este destino gente a propósito, se procure (dando al que lo sirva la comodidad y estimación posible) quitarle el honor con que comúnmente lo miran las personas que pudieran apetecerlo. A cuyo efecto a tiempo oportuno se fijarán carteles convocando a examen y ofreciendo lo que entonces se juzgue conveniente ${ }^{66}$.

Úbeda de los Cobos considera que esta propuesta "no pasó, en la práctica, de la mera enunciación" 67. En realidad, sí que se adoptó la propuesta de Mengs pero con algunos cambios y solo en parte. La bús-

61 Estatutos de la Real Academia de S. Fernando, Madrid, Gabriel Ramírez, 1757, p. 47.

62 Ibidem, pp. 49-51.

63 “Actas. Sesiones particulares”, ARABASF, leg. 3-121 (1757-1769), 9 de mayo de 1759, fol. 64r.

64 "Actas. Sesiones ordinarias", ARABASF, leg. 3-82 (1757-1769), 11 de febrero de 1763, fol. 164v.

65 “Actas. Sesiones particulares", ARABASF, leg. 3-121 (1757-1769), 27 de febrero de 1766, fol. 233v. Cfr. Andrés ÚBEDA DE LOS Coвos, "Propuestas de reforma y planes de estudio: la influencia de Mengs en la Real Academia de Bellas Artes de San Fernando", Archivo español de arte, LX, 240 (1987), pp. 447-462; Mercedes ÁGUEDA VILlaR, "Mengs y la Academia de San Fernando", en II Simposio sobre el Padre Feijoo y su siglo, Oviedo, Catedra Feijóo, 1983, vol. 2, pp. 445-476; Francisco José LEÓN TELLó e Isabel Ma LEÓN SANZ, "La contribución de Mengs a la estética de la pintura española", en I Congreso Internacional "Pintura Española siglo XVIII”, Marbella, Museo del Grabado Español Contemporáneo, 1998, pp. 425-433; Andrés Úbeda DE Los CoBos, Pintura, mentalidad e ideología en la Real Academia de Bellas Artes de San Fernando, 1741-1800, Madrid, Universidad Complutense, 1988.

66 "Actas. Sesiones particulares", ARABASF, leg. 3-121 (1757-1769), 27 de febrero de 1766, fol. 234v-235r.

67 Úbeda de los CoBos, 1987, p. 450. 
queda de nuevos modelos sí que se llevó a cabo, pero, por razones que desconocemos, no se presentó como iniciativa de Mengs sino de los profesores de la Real Academia. En efecto, en la Junta Ordinaria del 7 de septiembre de 1766 se indicó lo siguiente:

Haviendo representado todos los señores Profesores que los modelos de la Academia eran inútiles por haberse viciado mucho su configuración y que $\mathrm{p}[\mathrm{ar}] \mathrm{a}$ hacer los estudios con fruto era preciso buscar otro para dar principio al próximo curso, se acordó q[u]e los señores Castro y Calleja se encarguen de buscarlos ${ }^{68}$.

Así, se llevó a cabo la sustitución de los modelos existentes por otros mejor proporcionados, que además no fueran albañiles ya maduros sino soldados jóvenes y fuertes, como Manuel Herreros o José Guiñales. También se procuró, como había sugerido Mengs, darles mayor comodidad: en 1767 Castro indicó que los modelos pasaban mucho frío cuando posaban y que sería conveniente colocar unas cortinas en la Sala del Natural. La Junta no solo aprobó la idea, sino que indicó que se hicieran también "mamparas, canceles y todo lo demás que juzgue conveniente $\mathrm{p}$ [ar]a que aquella pieza quede con el resguardo y comodidades posibles", comisionando para esta labor a Ventura Rodríguez ${ }^{69}$.

Sin embargo, estas mejoras fueron medidas puntuales que no modificaron la consideración de los modelos ni sustituyeron lo recogido en los estatutos de 1757. De hecho, a pesar de la sugerencia de Mengs, no se redujo el número de modelos, posiblemente porque en los estatutos se recomendaba que los modelos fueran tres. Tampoco se pidió que estuvieran disponibles todo el día, sino solo por las noches, ni se les ofreció un aumento de sueldo. Y, cuando llegaron épocas de especial trabajo, nuevamente se requirió que los modelos ayudaran en las tareas domésticas.

Así ocurrió en 1774, cuando tuvo lugar el traslado de la Academia desde la Casa de la Panadería a la sede de la calle Alcalá. En esta ocasión, se pidió a los modelos que ayudaran en la mudanza de uno a otro edificio, encontrándose con la negativa tajante de uno de los modelos. Así, la junta del 9 de octubre de 1774 informó de que el modelo Gabriel Pérez,

es inutil por su floxedad y por sus vicios [...], ni para la mudanza de la Academia ni para otro trabajo de quantos en ella se ofrezen ha servido jam[a]s. Que haviéndole llamado el día 19 de sep[tiemb]re para ayudar al manejo de algunos muebles se negó y no ha vuelto a parezer ${ }^{70}$.

El resultado fue que Pérez fue despedido fulminantemente.

Sin embargo, la puesta en marcha de la nueva casa trajo consigo la existencia de mucho más espacio que mantener y limpiar, duplicando el trabajo de los porteros y barrenderos. Para repartir de forma igualitaria las tareas domésticas que debía hacer cada subalterno, en 1776, el conde de Pernia y el secretario, Ignacio de Hermosilla, trazaron un proyecto que buscaba repartir "menudamente las operaziones en que para el servicio y aseo de la casa se han de exercitar conserge, porteros, barrenderos y modelos"71. Esta instrucción volvía a incluir para los modelos la obligación de realizar el "barrido de patios, escaleras, Sala del Natural, encender el belón y los braseros"72, tareas que debían desempeñar en horario diurno.

\footnotetext{
68 “Actas. Sesiones ordinarias", ARABASF, leg. 3-82 (1757-1769), 7 de septiembre de 1766, fol. 397r.

69 "Actas. Sesiones ordinarias", ARABASF, leg. 3-82 (1757-1769), 6 de diciembre de 1767, fol. 444r y v.

70 “Actas. Sesiones ordinarias”, ARABASF, leg. 3-83 (1770-1775), 9 de octubre de 1774, fol. 301r.

71 “Actas. Sesiones particulares", ARABASF, leg. 3-123 (1776-1785), 1 de septiembre de 1776, fol. 19v-20r; 3 de noviembre de 1776 , fol. $31 \mathrm{v}$.

72 "Secretario general. Personal. Modelos", ARABASF, leg. 1-46-4 (1748-1856), 19 de enero de 1777, s/f.
} 
Nuevamente, los modelos protestaron por esta obligación, argumentando que cambiaba las condiciones con las que habían sido contratados y les impedía seguir trabajando durante el día ${ }^{73}$. El responsable del acuerdo, el conde de Pernia, decidió tomar como guía los estatutos de 1757, considerando que no se les estaba pidiendo a los modelos mucho más de lo que había previsto en dichos estatutos. Así que se denegó la solicitud de los modelos, aunque propuso una solución para que no tuvieran que acudir a la Academia durante el día: "podía reducirse la nueva obligación de los modelos a barrer la Sala del Natural dos veces a la semana y una, que podía ser los domingos por la mañana, los patios, pasos y escale/ras de la Academia y así no quedarán privados del jornal que en los días de trabajo dicen poder ganar"74. Además, dio orden de que cuando se aceptara a un modelo se le enviara al conserje para que le explicara bien sus obligaciones ${ }^{75}$. Este arreglo fue tomado como norma en adelante, aunque al parecer los modelos lograron, consuetudinariamente, quedar libres de parte de sus cargas, manteniendo solo "la del barrido de la escalera y patio pr[incip]al de la Academia, pues el natural lo barren los barrenderos y el patio de la fuente los aguadores"76.

El que los modelos realizaran tareas domésticas no era una situación exclusiva de la Real Academia de San Fernando. También en la Royal Academy británica era habitual compatibilizar el oficio de modelo con el de portero, aunque en 1804 se acordó que "los porteros no sean usados como modelos o por cualquier otro propósito"77. En cambio, al parecer, en la Académie francesa, la situación de los modelos era mucho más privilegiada: "Antes de la Revolución, los tres o cuatro modelos permanentes contratados por la Academia habían sido fonctionnaires reales. Constituían su propia jerarquía y el modelo de más edad era conocido como el Premier Modèle. Llevaban librea real y portaban una espada"78. Sin embargo, también allí la situación cambiaría en el siglo XIX, perdiéndose esos privilegios y limitándose la remuneración de los modelos al sueldo recibido.

\section{El sueldo de los modelos}

El hecho de que el trabajo de los modelos tuviera lugar solo durante unas horas al día hizo que el sueldo que cobraban fuese más bien bajo y, desde luego, insuficiente para vivir únicamente con él.

Durante el tiempo de la Junta Preparatoria, los dos modelos existentes, Pedro Díaz y Pablo Fernández, cobraban 3 reales por día, 1.100 reales al año, que se les había concedido el 20 de mayo de $1744^{79}$. En junio de 1747, aún durante la Junta Preparatoria, se les aumentó el sueldo a 1.450 reales al año, reconociendo que lo que se les pagaba "ciertamente es demasiado escaso para que se puedan sustentar y mantenerse de lo más preciso" $"$. Afortunadamente para ellos, en los años siguientes fueron consiguiendo algunos

\footnotetext{
73 “Actas. Sesiones particulares", ARABASF, leg. 3-123 (1776-1785), 19 de enero de 1777, fol. 36v; "Secretario general. Personal. Modelos", ARABASF, leg. 1-46-4 (1748-1856), 1777, s/f.

74 “Actas. Sesiones particulares", ARABASF, leg. 3-123 (1776-1785), 31 de enero de 1777, fol. 42v-43r.

75 "Secretario general. Personal. Modelos", ARABASF, leg. 1-46-4 (1748-1856), 28 de enero de 1777, s/f.

76 "Secretario general. Personal. Modelos", ARABASF, leg. 1-46-4 (1748-1856), 18 de abril de 1807, s/f. Para un nuevo intento, infructuoso también, por parte de los modelos de eximirse de las tareas domésticas, ver "Actas. Sesiones particulares", ARABASF, leg. 3-126 (1803-1814), 1 de marzo de 1807, fol. 229v-230r, y 5 de abril de 1807, fol. 233r y v: 1-46-4, 5 de marzo de 1807; "Secretario general. Personal. Modelos", ARABASF, leg. 1-46-4 (1748-1856), s/f (5 de abril de 1807,18 de abril de 1807 y 22 de abril de 1807).

77 "The Porters shall not be used as Models, or for any other purposes..." (traducción propia). DARLINGTON, 1990, nota 155.

78 "Prior to the Revolution, the three or four permanent models hired by the Académie had been royal fonctionnaires. They constituted their own hierarchy, and the senior model was known as the 'Premier Modèle'. They wore royal livery and carried a sword" (traducción propia). WALLER, 2002, p. 56.

79 "Secretario general. Personal. Modelos", ARABASF, leg. 1-46-4 (1748-1856), 20 de mayo de 1744, s/f.

80 "Secretario general. Personal. Modelos", ARABASF, leg. 1-46-4 (1748-1856), junio 1747-febrero 1748, s/f.
} 
pequeños aumentos que hicieron que en 1755 ya estuvieran cobrando 2.555 reales anuales, es decir, 7 reales y medio diarios ${ }^{81}$. Sin embargo, no pasaron muchos años antes de que la Junta se arrepintiera de este arranque de generosidad. En 1763, a consecuencia de un incidente, el Secretario revisó el sueldo que se estaba pagando a los modelos:

También expresé yo, que tenía por exorvitantes el sueldo de siete reales que se da a cada uno de ellos, quando en los principios de la Academia por quatro servía Pedro Díaz y otros que haviendo poco a poco conseguido aumentos de la piedad de los Señores Protectores habían llegado sus sueldos al exceso aprobado. De modo que repartido su haver en las noches que sirven se saca que por cada vez que se desnuda, viene a tener cada uno de ellos cinquenta reales de vellón ${ }^{82}$.

Ante estos antecedentes, la Junta tomó una decisión radical: cesar a los tres modelos y no contratar a ninguno por un sueldo diario: se contrataría a un modelo "para que sirva uno todas las noches y para las de Grupo dos o tres", y se les pagarían 12 reales "por cada noche que se desnuden, pero nada por las que no sirvieren" 83 .

El 1 de mayo de 1763, Andrés de la Calleja, Director General, opinó que podía resultar difícil encontrar modelos si no se les pagaba cuando no trabajaban. Así que la Junta propuso otra opción: que los modelos cobraran una peseta (4 reales) todos los días y otros 8 reales la noche en que tuvieran que desnudarse ${ }^{84}$. Este sueldo se mantuvo exactamente igual por lo menos hasta $1792^{85}$.

Aparte de ese sueldo, percibían periódicamente ayudas de costa, aunque siempre menos que otros subalternos de la Academia. En efecto, cada Navidad, la Academia repartía un aguinaldo a sus subordinados: 300 reales al Conserje, 150 a cada portero y 50 reales a cada modelo ${ }^{86}$. Inicialmente se les daba también una ayuda de costa tras los premios generales ${ }^{87}$, pero después esta gratificación pasó a darse al resto de subalternos pero no a los modelos ${ }^{88}$.

\section{La indisciplina de los modelos}

La baja consideración y el bajo sueldo hicieron que el trabajo de modelo no fuera muy estimado. A eso hay que añadir las dificultades de trabajar en ese puesto:

mayormente siendo su exercicio, no solo penoso, y de mucho trabajo personal, por las posturas extrañas a que se sugetan, a que se añade la dificultad de encontrar sujetos a propósito, y de buena formación para el intento, y la circunstancia de estar / obligados a hacer lo que les mandare el Conserge por lo que mira a los exercicios mecánicos del Sitio de la Academia, especialmente en los días de funciones públicas o extraordinarias ${ }^{89}$.

81 “Actas. Sesiones ordinarias", ARABASF, leg. 3-81 (1752-1757), 22 de octubre de 1755, fol. 40 r; cfr. 11 de julio de 1755 , fol. 39v; BÉDAT, 1989, p. 135.

82 “Actas. Sesiones ordinarias", ARABASF, leg. 3-82 (1757-1769), 11 de febrero de 1763, fol. 163v-164r.

83 "Actas. Sesiones ordinarias", ARABASF, leg. 3-82 (1757-1769), 11 de febrero de 1763, fol. 164r.

84 "Actas. Sesiones ordinarias", ARABASF, leg. 3-82 (1757-1769), 1 de mayo de 1763, fol. 169v-170r.

85 Diario de Madrid, 21 de diciembre de 1792, p. 1483.

86 “Actas. Sesiones particulares", ARABASF, leg. 3-121 (1757-1769), 17 de diciembre de 1758, fol. 48v; 10 de enero de 1760 , fol. 83 r; 13 de diciembre de 1760, fol. 109r; 17 de diciembre de 1761, fol. 121r; 5 de diciembre de 1762, fol. 142v; 20 de diciembre de 1768 , fol. 359v; 10 de diciembre de 1769, fol. 391r; leg. 3-122 (1770-1775), 1 de diciembre de 1771, fol. 84v, 6 de diciembre de 1772, fol. 134r y v; 4 de diciembre de 1764, fol. $224 \mathrm{r}$.

87 “Actas. Sesiones particulares", ARABASF, leg. 3-121 (1757-1769), 1 de febrero de 1758, fol. 5r.

88 "Actas. Sesiones particulares", ARABASF, leg. 3-122 (1770-1775), 25 de julio de 1772, fol. 116v.

89 "Secretario general. Personal. Modelos", ARABASF, leg. 1-46-4 (1748-1856), 1748, s/f. 
Esta queja sobre la dificultad de encontrar modelos es una constante en la documentación sobre el tema: Felipe de Castro comentaba en 1770 que "es mui difícil hallar un ombre completo y bien proporcionado en todas sus partes" $" 90$ y en 1781 el marqués de Florida Pimentel también subrayaba "la dificultad de encontrar sujetos de buenas proporciones que quieran sujetarse a este exercicio" 91 .

Por eso, la Academia acabará por contratar personas que puedan trabajar como modelos atendiendo solamente a su buen aspecto físico y a su disponibilidad para aceptar el trabajo incluso con su bajo sueldo, con el resultado de que, en ocasiones, los modelos contratados exhibían un comportamiento indigno, frecuentes faltas de disciplina y cometían delitos variados que llevaban incluso a su encarcelamiento ${ }^{92}$.

Podemos citar algunos de los ejemplos de los problemas ocasionados por los modelos entre 1752 y 1782. En 1763 surgió una disensión entre los modelos: Isidro Pareja y Antonio de Fuentes se quejaron de que "Pablo Fernández se finge enfermo para no asistir las semanas que le tocan, por lo que a ellos se recrece el trabajo que deja de hacer, estando al mismo tiempo bueno y sano para trabajar en Palacio". Sin embargo, la queja se volvió en su contra: "con motivo de esta súplica, hicieron presente algunos Señores Directores la indocilidad de estos modelos, principalmente de Antonio de Fuentes, a quien en modo alguno pueden reducir a que permanezca en las aptitudes más fáciles y descansadas" ${ }^{93}$. El resultado fue que la Academia decidió despedir a los tres modelos y posteriormente recontratar solo a Isidro Pareja y por un sueldo menor ${ }^{94}$.

En 1768 surgió un nuevo problema con otro modelo que tampoco parecía esforzarse lo suficiente:

Los directores hicieron presente $\mathrm{q}[\mathrm{u}] \mathrm{e}$ los modelos, especialmente, Julián Sánchez, no estaban tan obedientes como debían, desistiendo las aptitudes más descansadas, queriendo fueran a medida de sus caprichos. La Junta acordó que yo los llame, los reprenda y amoneste en el cumplimiento de su obligación, que obedezcan sin réplica como se manda en los Estatutos y que si buelben a dar motivo a la menor queja se les despedirá y entregará al Regimiento de Castilla al que se sacó de él ${ }^{95}$.

El último aviso iba dirigido a José Guiñales quien, como hemos dicho, era soldado en el Regimiento de Castilla hasta que se le conmutó este trabajo por el servicio como modelo. Y precisamente fue este modelo uno de los que más problemas ocasionó a la Academia por su comportamiento. En 1770 su madre escribió a la Academia informando de que a su hijo "se le llebó preso a la Cárcel de Corte p[o]r haberle cogido a deshora jugando y bebiendo en la casa de unas vez[in]as", pidiendo a la Academia que intercediera por él. Sin embargo, el conserje y porteros informaron "no ser esta la primera ni segunda vez, en que después de amonestado, ha sido preso por su vicio en el juego, el vino y la concurrencia a la casa donde lo prendieron", que no era exactamente la casa de unas vecinas sino "que es de mala nota". Además, los directores añadieron que el referido Guiñales "ha tiempo que no sirve como conviene no pudiendo conseguir el que subsista quieto en las aptitudes más cómodas y fáciles, de suerte que están mui desazonados con él quantos estudian en la Sala del Natural y muchos no quieren concurrir cuando él sirve, por lo qual y aun sin contar con los otros vicios, convendría despedirlo y buscar otro". Además, como había sido liberado del ejército por mediación del Conde de Aranda, se decidió informar a este para que regresara a su puesto original ${ }^{96}$.

\footnotetext{
90 "Secretario general. Personal. Modelos", ARABASF, leg. 1-46-4 (1748-1856), 23 de mayo de 1770, s/f.

91 "Secretario general. Personal. Modelos", ARABASF, leg. 1-46-4 (1748-1856), 25 de enero de 1781, s/f.

92 BÉDAT, 1989, p. 136; Federico Sopeña IBÁÑEz, "Historia”, en El libro de la Academia, Madrid, Real Academia de Bellas Artes de San Fernando, 1991, pp. 18.

93 “Actas. Sesiones ordinarias", ARABASF, leg. 3-82 (1757-1769), 11 de febrero de 1763, fol. 163v.

94 "Actas. Sesiones ordinarias", ARABASF, leg. 3-82 (1757-1769), 6 de marzo de 1763, fol. 170r.

95 “Actas. Sesiones ordinarias", ARABASF, leg. 3-82 (1757-1769), 20 de noviembre de 1768, fol. 507r.

96 “Actas. Sesiones ordinarias", ARABASF, leg. 3-83 (1770-1775), 6 de mayo de 1770, fol. 20v-21v; 10 de junio de 1770 , fol. 24v; "Secretario general. Personal. Modelos", ARABASF, leg. 1-46-4 (1748-1856), 1770, s/f; BÉDAT, 1989 , p. 136.
} 
Poco después, llegó a la Academia un memorial de Guiñales informando de que, tras el juicio previsto, "se declaró su inocencia, de suerte q[u]e se le mandó soltar libre y sin costas; y suplica que en esta atención se le vuelva a admitir por modelo de la Academ[i]a". Y la Academia, olvidando todos los motivos que había ido enunciando para despedirlo, "teniendo consideraz[i]on a que, como informaron los Direct[or]es es un buen modelo [...] acordó volverle a admitir"97.

En 1772, sin embargo, la situación volvió a complicarse. El 31 de mayo contó el Conserje:

que el día 4 solo pareció a la hora devida Salv[ad]or López, que puesta ya llegó Manuel Herreros y después de las nueve Joseph Guiñales, que al instante se retiró, que éste volvió la mañana del día 5 enteramente borracho y alvorotó su quarto, que cae frequentemente en este vicio y en otros, de suerte que escandaliza la Casa, siendo continuos los recursos de mujeres y otros por trampas, que todos lo tienen en la ma[i]or indecencia tomando cigarros y dando ocasión a $\mathrm{q}[\mathrm{u}] \mathrm{e}$ los discípulos hagan lo mismo.

La respuesta de la Junta fue sorprendentemente suave: pidió al director encargado de la Sala del Natural que les recordara la importancia de que estuvieran los tres puntualmente todas las noches, y que los multara con una peseta diaria cuando lo incumplieran ${ }^{98}$.

Sin embargo, pocos días después de recibir esta amonestación, Juan Pascual de Mena comunicó "que iendo a poner la figura, como $\operatorname{Dir}[$ ect]or de mes, la noche del día 2 del corriente [junio] no pareció modelo alguno, que el uno se escusó frívola y maliciosamente, que el otro de ellos no es capaz / de servir". Esta vez, la Junta sí que reaccionó con más dureza y propuso despedir a los tres, decisión que el Viceprotector aprobó. Solo se readmitió a Salvador López, en parte porque reiteró que no había acudido por estar realmente enfermo y en parte porque no se quería prescindir de él ya que "los S[eño]res González y Bayeu [...] lo tienen por mui bien formado" 99 .

Otro modelo que ocasionó bastantes problemas a la Academia fue José Rodrigo. En septiembre de 1775 fue despedido de su puesto por no haberse presentado tras las vacaciones de verano. Poco después, llegó un memorial suyo indicando que había viajado a su región, Aragón, sin pedir permiso por desconocimiento, y "que por haver estado preso injustamente en Daroca quando se restituía a servir su destino por septiembre de d[ic]ho año, y llevado desde allí a Zaragoza, no pudo venir a Madrid hasta ahora, que justificada su inocencia consiguió su libertad". Bayeu, que había visto al modelo en Zaragoza, confirmó su historia y se lo readmitió en el puesto ${ }^{100}$.

Dos años después, en 1777 volvieron a surgir problemas con José Rodrigo. Un alumno, llamado Pedro José Infanzón, de origen cubano y discípulo de Maella, se quejó a la Junta Particular de "uno de los modelos llamado Josef, que sin haberle dado motivo le mofó y burló una noche al concluir los estudios”. El propio alumno contó detalladamente el incidente:

estando en su respectiba sala [del Natural] al continuado estudio que es notorio y al concluirse d[ic]ho estudio e ir a tomar mi capa las noches pasadas, uno de los modelos nombrado Josef, sin conocerle yo ni menos aver tenido con el comunicasion [sic] ni familiaridad alguna, empezó a escarnecerme con burla y mofa en la d[ic]ha sala del natur[a]l en la cierta intelig[enci]a de no haverme metido con él ni aun dicho la mas leve palabra.

\footnotetext{
97 “Actas. Sesiones ordinarias", ARABASF, leg. 3-83 (1770-1775), 30 de septiembre de 1770, fol. 40r.; "Secretario general. Personal. Modelos", ARABASF, leg. 1-46-4 (1748-1856), 1770, s/f.

98 “Actas. Sesiones ordinarias", ARABASF, leg. 3-83 (1770-1775), 31 de mayo de 1772, fol. 120r-121r.

99 "Actas. Sesiones ordinarias", ARABASF, leg. 3-83 (1770-1775), 21 de junio de 1772, fol. 123r y v; 25 de julio de 1772 , fol. $147 \mathrm{v}$, y 3 de septiembre de 1772 , fol. $154 \mathrm{v}$.

100 “Actas. Sesiones ordinarias”, ARABASF, leg. 3-84 (1776-1785), 14 de abril de 1776, fol. 16r y v. "Actas. Sesiones ordinarias", ARABASF, leg. 3-84 (1776-1785), 14 de abril de 1776, fol. 17r.
} 
En esta ocasión, el conde Bournonville se ofreció a reprender al modelo ${ }^{101}$.

Poco después, en 1779, José Rodrigo fue nuevamente encarcelado, esta vez al parecer justamente, ya que tras el juicio fue condenado a presidio. Según él, el motivo era "preguntarle, donde paraba una andada del que expone, casada con Agustín Cavanillas, a cuia instancia fue preso, [...] y sin más causa q[u]e la $\mathrm{q}[\mathrm{u}] \mathrm{e}$ lleva expuesto se le ha sentenciado vaxo providencia quatro años a uno de los presidios de Africa" 102 . Inicialmente, la Academia trató de hacer algunas indagaciones sobre el delito por si podía apelar a la compasión del tribunal, pero al enterarse de la naturaleza de los delitos "no tuvo por conveniente interceder por el expresado modelo, ni consideró asequible el logro de lo que él pretendía"103.

El otro modelo encarcelado casi simultáneamente a José Rodrigo, fue Manuel González, llevado repentinamente a la Cárcel de Corte de la ciudad ${ }^{104}$. El motivo, según él, eran "informes falsos de bezindad sobre si entraba una moza en su aposento, [que] lo an tenido cuatro meses preso vendiéndole cuanto tenía y sentenciado seis años a presidio y abiendo justifi[ca]do lo contrario lo an echado a la calle dejándole al pobre en suma estrecheza sin mas anparo q[u]e el de Dios"105. A la salida de la cárcel solicitó a la Academia recuperar su puesto como modelo. Sin embargo, la Academia resolvió que dicha petición "no tuvo lugar por ignorarse la naturaleza de su causa, de la sentencia dada contra él, y haberse tenido presentes otras circunstancias" 106 .

La indisciplina de los modelos no era un asunto menor o una simple anécdota, más o menos humillante, para la Academia. El modelo de belleza que se quería que los modelos representaran tenía también un componente moral: no debía limitarse a un simple atractivo físico sino representar la importancia de la figura humana como centro y modelo de toda la creación: "la base conceptual para el trabajo a partir del modelo era la premisa de que las más grandes y nobles características de la humanidad se plasmaban físicamente en el desnudo masculino idealizado"107. Por esa razón, el sentido del dibujo de los modelos era "la perfección del arte (a través) de la imitación de la más selecta naturaleza"108, selecta naturaleza que era la que debían personificar los modelos.

Además, debemos tener en cuenta que pensadores de la época, como Winckelmann, consideraban que la belleza física de los antiguos griegos, precisamente la que se quería imitar, se debía a su forma de vida saludable, realizando deporte, en contacto con la naturaleza, y preparándose para el combate físico en defensa de su ciudad ${ }^{109}$. Tal vez por eso se recurrió en varias ocasiones a contratar soldados, una medida también habitual en otros países: en Gran Bretaña, un general, Robert Barton, favoreció que sus soldados fueran contratados como modelos para la Academia ${ }^{110}$. Probablemente se valoraba no solo que el ejercicio físico les permitiera tener buena figura, como sugería Winckelmann, sino que se les suponía una mayor disciplina y unos ideales más elevados de sentido del honor y defensa de la patria. El caso de José Guiñales demostró que estas ideas podían también ser erróneas.

101 “Secretario general. Personal. Modelos", ARABASF, leg. 1-46-4 (1748-1856), s/f; “Actas. Sesiones particulares”, ARABASF, leg. 3-123 (1776-1785), 3 de marzo de 1777, fol. 47v.

102 "Secretario general. Personal. Modelos", ARABASF, leg. 1-46-4 (1748-1856), 5 de abril de 1779.

103 “Actas. Sesiones particulares”, ARABASF, leg. 3-123 (1776-1785), 11 de abril de 1779, fol. 135v.

104 “Actas. Sesiones ordinarias”, ARABASF, leg. 3-84 (1776-1785), 7 de noviembre de 1779, fol. 138r.

105 "Secretario general. Personal. Modelos", ARABASF, leg. 1-46-4 (1748-1856), 1 de abril de 1780.

106 “Actas. Sesiones particulares”, ARABASF, leg. 3-123 (1776-1785), 2 de abril de 1780, fol. 193v-194r.

107 WALler, 2002, p. 45.

108 Ibidem, p. 47.

109 Johann Joachim Winckelmann, Reflexiones sobre la imitación del arte griego en la pintura y la escultura, Barcelona, Península, 1987, pp. 20-25.

110 "Henry Fusell's personal correspondence illuminates the fact that General Robert Barton had no objection to the two privates being engaged as Models in the life class". DARLINGTON, 1990, pp. 185-186. 
En esta línea de ejercitación del cuerpo, Darlington señala que en Londres un profesor de gimnasia se ofreció a instruir a uno de los modelos de la Royal Academy en varios ejercicios con el propósito de desarrollar su figura. La Royal Academy no solo aceptó el ofrecimiento, sino que pagó la gratificación del profesor durante el tiempo que durara el entrenamiento ${ }^{111}$, una medida que no consta que en ningún momento se tomara con los modelos españoles.

\section{Los desprecios e insultos a los modelos}

Además de los problemas que los modelos causaron, debemos tener en cuenta también los que ellos mismos sufrieron por parte de la población, sobre todo por personas de baja extracción social, para quienes un trabajo que requería desnudarse delante de gente solía estar asociado a alguna actividad indecente. De hecho, la simple necesidad de desnudarse se consideraba ya una acción tan indigna que, en las búsquedas de modelo, se pagaba a los aspirantes solo por el hecho de haberse desnudado: así, en 1770, Antonio González pide a Castro que examine a Santiago Martínez, "dándole por su trabajo la propina acostumbrada" y este le confirma al Director: "Registré desnudo al referido pretendiente de modelo Santiago Martínez $\mathrm{y}[\ldots]$ dile un peso fuerte $\mathrm{p}[\mathrm{o}] \mathrm{r}$ averse desnudado"112.

Los modelos de la Real Academia sufrieron con frecuencia el desprecio que acarreaba dicha concepción, como nos ilustran algunas anécdotas. En 1775, los modelos se quejaron de que "de poco tiempo a esta parte ha dejado la Guardia entrar mucha gente indecente como aceyteros, chisperos, mozos de trabajo, arrieros, calesineros y otros que hacen burla y se están riendo de las aptitudes o posiciones en q[u]e los colocan los directores"113. Aunque se dio orden de que se prohibiese la entrada a estas personas, no debió de cumplirse exactamente esta orden, porque aún en 1807, el modelo Juan López pedía "que se diese orden de que en la Sala del Natural no entren personas indecentes ni muchachos"114.

El expediente sobre los modelos muestra otras denuncias similares, posteriores a nuestro marco cronológico, pero que permiten ver la amplitud de estas acciones injuriosas. En 1793, el modelo José Pérez presentó una queja contra "Francisco Vega, peón de alvañil, sobre haver en su ausencia hecho mofa de su oficio, q[u]e era ruin y bajo con otras proposiciones injuriosas..."115. En 1795, otro modelo, Antonio Picazo, informó de que en su pueblo insultaban a su familia por ser "oficio ruin y ocupación baxa la de servir de modelo de perfección en la Academia"116. Y en 1802 otro modelo, Ramón Fernández Castañeda, hizo saber que un vecino suyo le había calificado de "hombre sin verguenza, sin honra ni estimación, q[u]e se pone en cueros enseñando cuanto tiene para ganar de comer"117.

El propio Fernández Castañeda había protagonizado un caso similar en 1800 cuando recibió una patética carta de su esposa que transcribimos por su interés:

Encontré con el hijo de Diegon de Soirana y le pregunte por ti y me dijo delante de tu hermana Rosa, de tu prima Isabel y de otras varias personas que tu amo te daría cinco (corregido de cuatro) rr[eale]s cada día y tu que para

\footnotetext{
111 "Mon. Clias, Professor of Gymnastics, from Berne, having offer'd to instruct one of the models of the Academy in various exercises for the purpose of developing his form - Resolved, that N. Clias be engaged for that purpose at the rate of 50 guineas for 6 weeks". DARLington, 1990, p. 186.

112 "Secretario general. Personal. Modelos", ARABASF, leg. 1-46-4 (1748-1856), 1770, s/f.

113 “Actas. Sesiones ordinarias”, ARABASF, leg. 3-83 (1770-1775), 4 de junio de 1775, fol. 366v-367r; 9 de julio de 1775 , fol. 369r; BÉDAT, 1989, p. 137.

114 “Actas. Sesiones particulares”, ARABASF, leg. 3-126 (1803-1814), 1 de marzo de 1807, fol. 229v-230r.

115 "Secretario general. Personal. Modelos", ARABASF, leg. 1-46-4 (1748-1856), 15 de junio de 1793, s/f.

116 “Actas. Sesiones particulares”, ARABASF, leg. 3-125 (1795-1802), 3 de mayo de 1795, fol. 12r; BÉDAT, 1989 , p. 137.

117 "Secretario general. Personal. Modelos", ARABASF, leg. 1-46-4 (1748-1856), 30 de septiembre de 1802, s/f; "Actas. Sesiones particulares", ARABASF, leg. 3-125 (1795-1802), 3 de octubre de 1802, fol. 228r. Cfr. NAVARRETE MARTíneZ, 1999 , p. 147.
} 
ganar otros cinco en ese enpleo de portero que te es preciso ponerte en cueros todas las noches como lo hacen todos los señores y señoras que entran en esa casa, $[\ldots]$ cosa $\mathrm{q}[\mathrm{u}] \mathrm{e}$ me tiene tan sobre salteada que no puedo descansar de noche y dia ${ }^{118}$.

Llama la atención que, al parecer, Castañeda no se había atrevido a decirle a su mujer en qué consistía su trabajo, por lo que ella estaba en la idea de que se trataba de un "empleo de portero".

La Academia intervino siempre en estos casos en defensa de los modelos. Posiblemente, la razón era que las maledicencias contra ellos también afectaban a la imagen de la Academia: ya vemos en la carta de la esposa de Castañeda que esta imaginaba que en ella se desnudaban "todos los señores y señoras que entran en esa casa". Por ello, la Academia trataba de insistir en la dignidad de los modelos, que trabajaban por una causa tan loable como era el avance de las Bellas Artes. Así, en el juicio al citado peón de albañil Vegas en 1793, parece ser que Vegas fue adoctrinado sobre qué debía decir en el juicio, y así se defendió indicando que su intención no era ofender porque "reconocía por la nobleza de las tres bellas artes q[u]e era muy honesta y noble la ocupación / de quantos se ejercitaban y empleaban en ellas, sin que de modo alguno pueda infamarles menguar su honra y estimación a los modelos"119. Además, en la Academia consideraban que debían intervenir en defensa de los modelos para que estos no dejaran de trabajar como tales: "Nunca ha mirado la Acad[emi] a con indiferencia estos recursos de los Modelos, pues de desatenderlos se seguirían gravísimos perjuicios, como sería el de retraerse del servicio, no encontrar quien quisiera exercer este empleo y causar notorios atrasos al adelantam[ien]to de las artes, que estriban en el estudio continuo de la naturaleza"120.

A pesar de estas continuadas defensas, la opinión de los propios académicos, en especial de los consiliarios, podía llegar a ser igual de denigratoria. Podemos citar como ejemplo un comentario realizado a propósito del llamado "caso Graef”'121. En 1759 surgió una discusión en la Academia al enfrentarse Felipe de Castro y Ventura Rodríguez con un visitante llamado Graef y colocarlo en el cepo. La Junta Particular, preocupada, decidió interrogar a todos los posibles testigos, pero aunque recabó la opinión de otros profesores, el conserje y los porteros, decidió no interrogar ni a los alumnos ni a los modelos, "porque el espíritu de parcialidad de estas gentes suele ofuscar la verdad" 122 .

\section{La "jubilación" de los modelos}

El último aspecto que trataremos sobre el día a día de los modelos es el relativo a su despido o jubilación $^{123}$. Las razones por las que un modelo dejaba de trabajar como tal eran variadas. Entre 1752 y 1782 , solo uno de los modelos falleció cuando aún estaba desempeñando su oficio: Francisco Paisá. Del resto, como hemos dicho, al menos dos modelos dejaron de trabajar por haber sido encarcelados (José Rodrigo y Manuel González). Y seis fueron despedidos por desobediencias flagrantes: Antonio de Fuentes, Pablo Fernández, Julián Sánchez, José Guiñales, Manuel Herreros y Gabriel Pérez. Solo uno de los modelos, Juan del Valle, dimitió voluntariamente.

\footnotetext{
118 "Secretario general. Personal. Modelos", ARABASF, leg. 1-46-4 (1748-1856), 1800, s/f; “Actas. Sesiones particulares", ARABASF, leg. 3-125 (1795-1802), 5 de enero de 1800, fol. 142r y v; BÉDAT, 1989, p. 137.

119 “Actas. Sesiones particulares", ARABASF, leg. 3-125 (1795-1802), 3 de mayo de 1795, fol. 12r.

120 "Secretario general. Personal. Modelos", ARABASF, leg. 1-46-4 (1748-1856), s/f.; "Actas. Sesiones particulares", ARABASF, leg. 3-125 (1795-1802), 3 de octubre de 1802, fol. 228r.

121 Sobre el caso Graef, ver por ejemplo Carlos SAMBricio, "Ventura Rodríguez en Valladolid: el informe de la Catedral y la transformación radical de su pensamiento historicista", en Informe que hizo el arquitecto de S.M. D. Ventura Rodríguez en el año de 1768, de la Santa Iglesia de Valladolid, Valladolid, Colegio Oficial de Arquitectos de Valladolid, 1987, pp. 17-22.

122 “Actas. Sesiones particulares", ARABASF, leg. 3-121 (1757-1769), 18 de octubre de 1759, fol. 74r.

123 BÉDAT, 1989, p. 136.
} 
Sin embargo, lo más habitual era que los modelos fueran despedidos cuando ya no podían seguir ejerciendo como tales. Así, dos de ellos fueron despedidos por las consecuencias de su elevada edad: Pedro Díaz tras quince años e Isidro Pareja tras seis. A ellos se pueden añadir otros tres: Bartolomé López, que solo estuvo tres años pero a quien se despidió por no estar suficientemente bien formado, Juan de Soto, que renunció al cargo pero por encontrarse demasiado enfermo y cansado, y Salvador López, quien trabajó durante dieciocho años aunque finalmente parece que el motivo de su partida se debió a haber sido designado para otro cargo. Otro motivo de despido era haber perdido la buena figura: así, Juan del Valle fue despedido "por haber engordado demasiado de vientre" 124.

Puede sorprender que haya modelos que trabajaran como tales quince o dieciocho años, pero el aumento de edad, aunque evidentemente quitara a sus figuras la frescura de la juventud, aportaba otros valores a los modelos. En el caso francés, se cita el ejemplo de un modelo que trabajó en la Académie Royale desde 1725 a 1772, es decir, cuarenta y siete años. Y apunta Susan Waller: "presumiblemente, fue contratado inicialmente porque personificaba la belle nature, pero lo prolongado de su trabajo sugiere que su conocimiento y experiencia pesaban más que el envejecimiento de su cuerpo"125. Una idea en la que insiste esta misma autora al hablar de los beneficios que aportaban los modelos "que han envejecido en la profesión (...): sus músculos son resistentes, flexibles e inteligentes, entiende la más mínima sugerencia, sabe cómo expresar las emociones (...) y entiende los términos técnicos tanto como el argot del taller"126.

La Academia no tenía en el reglamento una recomendación concreta sobre cómo tratar a los modelos que dejaban de serlo, por lo que según cada caso tomó unas decisiones u otras. Esta actitud le trajo algunas disensiones con antiguos modelos que reclamaban para sí el mismo tratamiento que se les había dispensado a otros modelos anteriores.

Inicialmente, a los modelos que habían servido durante mucho tiempo y eran despedidos por haber envejecido, se les concedía una pensión monetaria. Así, uno de los primeros modelos, Pedro Díaz, fue despedido en 1760 ya que "por su avanzada edad, y lo mucho que ha servido, está ya desfigurada su buena proporción e inútil para modelo" 127 . En este caso, a Pedro Díaz se le concedió seguir cobrando una pensión de 4 reales diarios hasta que se encontrara a otro modelo. En realidad, la pensión no se prolongó mucho porque Díaz falleció al mes siguiente ${ }^{128}$. Y algo parecido ocurrió en 1770, cuando Julián de Soto presentó su renuncia por hallarse ya cansado y falto de salud pero pedía una ayuda de costa para poder mantener a su familia ${ }^{129}$.

En otros casos la ayuda económica se concedía solo durante un tiempo determinado: a Juan del Valle, en 1782, se le concedió una peseta diaria desde marzo, en que fue despedido, hasta agosto, para que se mantuviera hasta que encontrara otro trabajo ${ }^{130}$. Y en otras ocasiones la ayuda era puntual para poder regresar desde Madrid a su localidad de origen. Así ocurrió con otro de los primeros modelos, Pablo Fernández. Fernández fue despedido en 1763 tras ser acusado por sus compañeros de fingirse enfermo

\footnotetext{
124 Para todos estos casos, ver "Secretario general. Personal. Modelos", ARABASF, leg. 1-46-4 (1748-1856), s/f. Cfr. NAVARrete MartíneZ, 1999, p. 146.

125 "Presumably he was hired initially because he embodied la belle nature, but the length of his tenure suggests that his knowledge and experience outweighed changes to his aging body" (traducción propia). WALLER, 2002, p. 55.

126 "His muscles are tireless, supple and intelligent; he understands the least suggestion. He knew how to express all the emotions (...) and he understood technical terms as well as atelier slang" (traducción propia). WALLER, 2002, p. 60.

127 “Actas. Sesiones ordinarias", ARABASF, leg. 3-82 (1757-1769), 28 de octubre de 1760, fol. 100r; "Secretario general. Personal. Modelos", ARABASF, leg. 1-46-4 (1748-1856), 1760, s/f.

128 "Secretario general. Personal. Modelos", ARABASF, leg. 1-46-4 (1748-1856), 28 de octubre de 1760, s/f; 30 de noviembre de $1766, \mathrm{~s} / \mathrm{f}$.

129 "Secretario general. Personal. Modelos", ARABASF, leg. 1-46-4 (1748-1856), 10 de junio de 1770, s/f.

130 "Secretario general. Personal. Modelos", ARABASF, leg. 1-46-4 (1748-1856), 25 de julio de 1782, s/f; "Actas. Sesiones particulares", ARABASF, leg. 3-123 (1776-1785), 6 de octubre de 1782, fol. 235v-236r.
} 
por no trabajar ${ }^{131}$. Fernández escribió a la Academia asegurando que, por encontrarse verdaderamente enfermo, viudo y con tres hijos, solicitaba una ayuda de costa para regresar a su tierra natal, Galicia. La Academia decidió concederle 1.500 reales para el viaje ${ }^{132}$. Sin embargo, Fernández no llegó a cobrarlos ya que falleció poco después, dejando huérfanos a sus tres hijos, de dieciséis, seis y cinco años. El marqués de Villafranca decidió buscar un destino a los dos pequeños, considerando que el mayor ya podría ganarse la vida por sí mismo ${ }^{133}$. Podemos señalar que también a otro modelo, Bartolomé Díaz, se le concedió en 1766 una pensión para restituirse a su tierra ${ }^{134}$.

Un punto de inflexión lo constituyó el caso de Isidro Pareja. Este modelo fue jubilado en 1766 tras muchos años de trabajo, así que solicitó a la Academia la pensión de una peseta que hasta hacía poco se había pagado a Pedro Díaz, recientemente fallecido. La Junta Particular accedió a su petición, pero pidió a Pareja que, a cambio de esa peseta, desempeñara labores domésticas, como asear la casa, limpiar candeleros y encender braseros ${ }^{135}$. Así, Pareja pasó a convertirse en uno de los barrenderos de la Academia, puesto que mantuvo hasta su muerte en $1780^{136}$.

A partir de ese momento, fue bastante habitual que los modelos jubilados pasaran a desempeñar otros trabajos en la Academia. Salvador López, cuando pidió en 1780 su jubilación, pidió trabajar como barrendero, como hemos visto ${ }^{137}$. Y lo mismo ocurrió con Julián López en 1792 o con Mariano Superi, ambos contratados como barrenderos cuando ya no podían servir como modelos ${ }^{138}$. Otros, como Ignacio Pons en 1825 o José Álamo en 1845, solicitaron ser admitidos como porteros tras un tiempo sirviendo como modelos, aunque no consta que se les concediera a ninguno de los $\operatorname{dos}^{139}$.

Sin embargo, la Academia no consideró que este paso de modelo a barrendero o portero tuviera que ser algo automático, sino que dependía de la valía de los modelos. Cuando en 1782 fue despedido Juan del Valle, este reclamó seguir trabajando en la Academia como barrendero, como se hacía con "los modelos que han cumplido bien y el tiempo los ha inutilizado"140. Pero la Academia rechazó este argumento, probando, con la ayuda del portero, Juan Moreno, que en toda la historia de la Academia solo un modelo (Pareja) había sido destinado a barrendero tras jubilarse, por lo que no era en absoluto una costumbre generalizada $^{141}$.

También fue rechazada por similares motivos la petición de otro de los modelos en activo durante la época de este estudio: José Guiñales. Como se recordará, este modelo había sido despedido por su conducta inmoral y sus frecuentes ausencias. En 1803, sin embargo, pidió a la Academia una hipotética pensión asignada a los modelos, indicando que no la había solicitado en 1772 cuando abandonó la Academia (según él, para "vender un poco de hacienda") por no necesitarla entonces, pero al encontrarse en esos momentos "en la más deplorable miseria [...] siendo ya un pobre anciano, sin tener con que mantener-

\footnotetext{
131 “Actas. Sesiones ordinarias", ARABASF, leg. 3-82 (1757-1769), 11 de febrero de 1763, fol. 163v.

132 "Actas. Sesiones ordinarias", ARABASF, leg. 3-82 (1757-1769), 19 de junio de 1763, fol. 177v.

133 "Actas. Sesiones ordinarias", ARABASF, leg. 3-82 (1757-1769), 7 de agosto de 1763, fol. 195v-196r.

134 "Actas. Sesiones ordinarias", ARABASF, leg. 3-82 (1757-1769), 2 de noviembre de 1766, fol. 412r-412v; "Actas. Sesiones particulares", ARABASF, leg. 3-121 (1757-1769), 14 de diciembre de 1766, fol. 278r; "Secretario general. Personal. Modelos", ARABASF, leg. 1-46-4 (1748-1856), 14 de diciembre de 1766, s/f.

135 “Actas. Sesiones particulares”, ARABASF, leg. 3-121 (1757-1769), 14 de diciembre de 1766, fol. 278 r y v.

136 “Actas. Sesiones particulares”, ARABASF, leg., 3-123 (1776-1785), 5 de noviembre de 1780, fol. 201r.

137 "Secretario general. Personal. Modelos", ARABASF, leg. 1-46-4 (1748-1856), 5 de noviembre de 1780, s/f.

138 "Secretario general. Personal. Modelos", ARABASF, leg. 1-46-4 (1748-1856), s/f.

139 "Secretario general. Personal. Porteros, conserjes y mozos", ARABASF, leg. 1-45-4 (1745-1845), 3 de octubre de 1825 y 24 de mayo de 1845 , s/f.

140 "Secretario general. Personal. Modelos", ARABASF, leg. 1-46-4 (1748-1856), 25 de julio de 1782, s/f; “Actas. Sesiones particulares", ARABASF, leg. 3-123 (1776-1785), 6 de octubre de 1782, fol. 235v-236r.

141 “Actas. Sesiones particulares”, ARABASF, leg. 3-123 (1776-1785), 6 de octubre de 1782, fol. 236r.
} 
me...", pedía que se le pagara lo que le había correspondido en su momento. La Academia, que no parecía haber olvidado a Guiñales, rechazó enérgicamente la petición y aunque Guiñales volvió a presentarla solo un mes después, fue nuevamente rechazada por la Academia ${ }^{142}$.

\section{Conclusión}

Como vemos, por lo tanto, hasta 1782 la situación de los modelos experimentó pocos cambios respecto a su institución en 1752: su sueldo apenas había variado (incluso se había reducido en 1763), seguían teniendo que desempeñar tareas domésticas en la Academia y su consideración social seguía siendo muy baja, tanto dentro como fuera de la Academia, provocando la contratación de personas de vida disipada que con frecuencia eran despedidos o incluso encarcelados. El resultado era una gran inestabilidad entre los modelos que redundaba, como se ha señalado, en problemas para el aprendizaje de los estudiantes, que se encontraban a veces sin un modelo que posara para ellos o que se retraían de acudir a la Sala del Natural cuando tocaba posar a modelos especialmente problemáticos, de los que en ocasiones llegaron a recibir incluso insultos.

Tal vez por todo ello, Ceán Bermúdez señalaba que hasta 1794 no había tenido lugar el "arreglo" del natural vivo. En aquella ocasión, según cuenta, se publicó la necesidad de modelos para la Academia y se presentaron "entre veinte y seis mozos bien formados se examinaron sus desnudos, y fueron elegidos dos, que con el que antes habia completaron las tres clases necesarias a este estudio"143. Como hemos visto, a pesar del entusiasmo de Ceán, tampoco estos modelos ganaron en consideración y prestigio, ya que siguieron viéndose envueltos en reyertas e insultos durante buena parte del siglo XIX.

En la Academia, sin embargo, el papel de los modelos sí que parecía ir siendo cada vez más valorado. En 1844 se estableció un plan de enseñanza de las Bellas Artes en el que se indicaba que: "es escusado encarecer la importancia de esta regla, siendo un principio inconcuso que el estudio constante y esmerado del modelo vivo es la base fundamental de las Artes que se fundan en el dibujo de la figura humana". En esta época, sin embargo, se había introducido un cambio fundamental en las características de los modelos seleccionados: en vez de seguir buscando jóvenes robustos y bien formados se estipuló que los tres modelos debían ajustarse cada uno a una edad diferente del hombre: un joven (se buscaba una persona de unos dieciséis años), un hombre maduro y un anciano, en un interés por el realismo adecuado a las corrientes románticas introducidas en esas fechas ${ }^{144}$. De hecho, esta misma tendencia se apreciaba en otras academias: en Londres, en 1810, "los académicos creían que los modelos empleados para la Sala del Natural debían ser tan diversos en carácter como fuera posible"145. Y en Francia estas medidas habían empezado a tomarse en una fecha tan temprana como es 1777: "Son necesarios varios modelos de diferentes edades y caracteres... de lo contario, incluso la imitación de la naturaleza acaba por ser amanerada"146.

142 “Secretario general. Personal. Modelos", ARABASF, leg. 1-46-4 (1748-1856), 25 de abril de 1803, s/f, y 1 de junio de 1803, s/f; “Actas. Sesiones particulares”, ARABASF, leg. 3-126 (1803-1814), 1 de mayo de 1803, fol. 15v, y 5 de junio de 1803, fol. $18 \mathrm{v}$.

143 Juan Agustín Cé́n Bermúdez, "Historia de la Real Academia de Nobles Artes de San Fernando", Academia, 21 (1965), p. 70. Citado por CAVEDA, 1867, pp. 293-294.

144 "Secretario general. Personal. Modelos", ARABASF, leg. 1-46-4 (1748-1856), 11 de octubre de 1856, s/f; CIRUELOS GonZALO, 1994, p. 140.

145 "Models were in great demand and Academicians believed that models employed for the life class should be as diverse in character as possible: for instance, it was once required that there be provided 'as speadily as possible two additional Male Models for the Life Academy the one a more youthful character, the other in the prime of manhood"' (traducción propia). DARLINGTON, 1990, p. 185.

146 "Several models of different ages and characters are necessary... otherwise even work after nature may become mannered" (traducción propia). WALLER, 2002, p. 55. 
Por otro lado, el crecimiento de los jóvenes que estudiaban en la Academia provocó también una necesidad de un mayor número de modelos: así, en 1856 se decidió doblar a seis el número de modelos por ser insuficientes los tres previstos para servir a toda la Academia ${ }^{147}$.

Como vemos, por lo tanto, se da la paradoja de que la necesidad de modelos masculinos para la Sala del Natural, que surgió por el interés por el mundo antiguo característico del Neoclasicismo (y antes del Renacimiento) solo se consolidó en el siglo XIX, cuando ya ese ideal estético había quedado superado.

MYRIAM FERREIRA FERNÁNDEZ es Doctora en Historia del Arte por la Universidad de La Rioja (2008) y profesora en la Universidad Internacional de La Rioja (UNIR) desde 2010, donde imparte diversas asignaturas relacionadas con la historia del arte en el Grado en Humanidades, además de ser la coordinadora académica de dicho Grado. Es autora de una monografía publicada en 2014 (Los Ágreda: la evolución de la escultura del taller barroco a la Academia neoclásica) y coautora de otras dos monografías (El cementerio municipal de Logroño, 2009, y Fray José de San Juan de la Cruz y el arte rococó en La Rioja, 2018), las tres publicadas por el Instituto de Estudios Riojanos. Además, ha publicado diversos artículos en revistas científicas como Archivo Español de Arte, BSAA: Arte, Academia, Boletín del Museo e Instituto Camón Aznar, Ars Bilduma, Berceo o Trocadero, sobre artistas de los siglos XVIII y XIX, fundamentalmente ligados al ámbito académico. Forma parte del proyecto de investigación “ACAF/ART 4: Cartografías críticas, analíticas y selectivas del entorno artístico y monumental del área mediterránea en la Edad Moderna" de la Universidad de Barcelona.

Email: myriam.ferreira@unir.net

Código ORCID: https://orcid.org/0000-0002-5782-5033

147 "Secretario general. Personal. Modelos", ARABASF, leg. 1-46-4 (1748-1856), 11 de octubre de 1856, s/f. 